\title{
Após o fim de um relacionamento amoroso: uma revisão narrativa
}

\author{
After the breakup: a narrative review
}

\section{Rodrigo Barbosa Nascimento $^{\ominus}$, Emanuel Santos de Araujo Filho ${ }^{2} \theta$, Gabriela de Lima Cerqueira ${ }^{3} \bullet$, Daniela Gomes Carneiro $^{4}$, Emilly Santos da Silva Carmo $^{50}$}

\footnotetext{
${ }^{1}$ Acadêmico do curso de Psicologia da Escola de Ciências da Saúde e Bem-estar da Universidade Salvador - Laureate International Universities, Feira de Santana, Bahia, Brasil. Graduando em Filosofia pela Universidade Católica de Brasília, Brasil. ${ }^{2}$ Acadêmico do curso de Psicologia da Escola de Ciências da Saúde e Bem-Estar da Universidade Salvador - Laureate International Universities, Feira de Santana, Bahia, Brasil. *Autor para correspondência. E-mail: nascimentolag@gmail.com
}

Resumo: Introdução: Relacionamentos são considerados demasiadamente importantes e se constituem como parte da formação, amadurecimento e processo de desenvolvimento da vida humana. Objetivo: Sendo assim, o presente artigo objetiva compreender os possíveis impactos dos términos de relacionamentos amorosos e suas implicações emocionais e comportamentais na vida do sujeito. Método: Para tal, foi realizada uma revisão narrativa de literatura (RNL) dividida em três etapas, sendo a primeira: o processo de busca inicial, a segunda: a exclusão de artigos sem os critérios elegíveis para inclusão, e a terceira: leitura completa dos artigos restantes. Foram eleitos 32 artigos para a amostra final desse estudo. Resultados: Diante de evidências sistematicamente coletadas, pode-se perceber que as alterações no pós-rompimento de relacionamento amoroso, a nível psicológico, podem ser compreendidas de duas formas: positivas e negativas. Destacando-se na primeira: sensação de alívio, memórias positivas, sentimento de liberdade, e na segunda: a prevalência de ansiedade, depressão, angústia, raiva, tristeza, luto, baixa autoestima e a sensação de desamparo. Em relação às alterações comportamentais, foi perceptível comportamentos de perseguição, provocação e criminoso. Considerações finais: Conclui-se, portanto, que os relacionamentos amorosos apresentam implicações significativas na vida daquele que passa, sobretudo do ponto de vista dos impactos psicológicos negativos e comportamentais, não obstante haja efeitos psicológicos positivos consideráveis e passíveis de maiores investigações. Além disso, através do mapeamento dos achados acerca das implicações psicológicas e comportamentais do término de um relacionamento amoroso, tornou-se possível organizar em único local os principais achados que corroboram para a elucidação e ampliação do debate referente a tal temática, resultando, portanto, em uma maior acessibilidade a essas informações, sobretudo no âmbito da literatura brasileira.

Palavras-chave: angústia psicológica, relacionamento amoroso, término do relacionamento amoroso, sintomas psicológicos, comportamento.

\begin{abstract}
Introduction: Relationships are considered extremely important and constitute part of the formation, maturation and development process of human life. Objective: Therefore, this article aims to understand the possible impacts of ending love relationships and their emotional and behavioral implications in the subject's life. Method: To this end, a narrative literature review was carried out divided into three stages, the first: the initial search process, the second: the exclusion of articles without the eligible criteria for inclusion, and the third: full reading of the remaining articles. 32 articles were chosen for the final sample of this study. Results: In view of the evidence systematically collected, it can be seen that the changes in the post-breakup of a love relationship, at a psychological level, can be understood in two ways: positive and negative. Standing out in the first: feeling of relief, positive memories, feeling of freedom, and in the second: the prevalence of anxiety, depression, anguish, anger, sadness, grief, low selfesteem and the feeling of helplessness. Regarding behavioral changes, harassment, provocation and criminal behaviors were noticeable. Final considerations: It is concluded, therefore, that love relationships have significant implications in the life of those who pass by, especially from the point of view of negative psychological and behavioral impacts, despite considerable positive psychological effects that are subject to further investigation. In addition, by mapping the findings about the psychological and behavioral implications of the end of a love relationship, it became possible to organize in a single place the main findings that corroborate for the elucidation and expansion of the debate regarding this theme, resulting, therefore, in greater accessibility to this information, especially in the context of Brazilian literature.
\end{abstract}

Keywords: psychological distress, romantic relationship, romantic relationship breakup, psychological symptoms, behavior. 


\section{Introdução}

Os relacionamentos amorosos são considerados como parte da formação pessoal de qualquer sujeito; em outras palavras, possui um papel relevante no amadurecimento e no processo de desenvolvimento da vida humana.

Contudo, embora exerça esse papel, os relacionamentos amorosos geram desafios para aquele que o vivencia, e um desses é a experiência do rompimento (término, separação) deste (Alexander, 2008). Embora a experiência do rompimento possa ser considerada comum (Robak \& Weitzman, 1998), é ao mesmo tempo uma experiência dolorosa. De acordo com Mason et al. (2012), o rompimento de um relacionamento amoroso pode ser compreendido como uma das experiências com maiores níveis de estresse, sofrimento e perturbação da vida humana.

Para além disso, as experiências de términos de relacionamentos românticos apresentam certas implicações emocionais e comportamentais subsequentes, diferindo de pessoa para pessoa. Em casos mais elevados, os sofrimentos são tão intensos e constantes, que podem vir a ocasionar o desenvolvimento de transtornos psiquiátricos ou agravamento destes (Francoeur, 2020).

Desse modo, é, então, devido à centralidade que os relacionamentos amorosos possui na vida humana e como este pode estar envolvido tanto no desenvolvimento e agravamento de transtornos psiquiátricos, assim como em grandes estados de sofrimento psíquico e mudanças comportamentais, que esse estudo se configura como de demasiada importância para compreender as nuances que envolvem o rompimento dos relacionamentos e, de maneira mais específica, quais de fato são as implicações do rompimento na vida de uma pessoa, proporcionando também acesso a essas informações na literatura brasileira.

Sendo assim, a partir de uma revisão narrativa, o presente artigo objetivou organizar e elucidar as principais evidências científicas publicadas entre 2006 e 2021 acerca das implicações psicológicas e comportamentais resultantes de términos de relacionamentos amorosos.

\section{Revisão e discussão}

\section{Delineamento metodológico}

Mediante a construção de uma revisão narrativa de literatura (RNL), o presente artigo se propôs a apresentar sistematicamente evidências científicas acerca das possíveis implicações psicológicas e comportamentais resultantes de términos de relacionamentos. A elaboração desse tipo de estudo contempla seu caráter amplo e normalmente se propõe a descrever o desenvolvimento de uma determinada questão (de um ponto de vista teórico ou contextual), através da análise e interpretação da literatura científica publicada (Vosgerau \& Romanowski, 2014). Embora a literatura, por vez, faça menção à não transparência do percurso de pesquisa desse tipo de estudo, ou seja, à não explicitação de fontes de informação, metodologia para a busca dos estudos e os critérios utilizados para seleção e avaliação (Rother, 2007), a presente revisão buscou apresentar os passos de sua construção por motivos de transparência e detalhamento metodológico.

O primeiro passo para o desenvolvimento dessa revisão partiu da construção do detalhamento metodológico no qual encontra-se a pergunta norteadora: “Quais implicações psicológicas e comportamentais o término de um relacionamento ocasiona?”. Em seguida, foram pesquisados no DeCS (Descritores em Ciências da Saúde) alguns descritores para realizar a busca em bases de dados. Foram encontrados os descritores: Angústia Psicológica (Psychological Distress); Relacionamento Amoroso (Romantic relationship); Término do Relacionamento Amoroso (Romantic Relationship breakup); Sintomas Psicológicos (Psychological Symptoms); Comportamento (Behavior). Aqueles descritores que não foram encontrados no DeCS foram acrescentados de acordo com a sua relação com a proposta desse estudo através da consulta de outros artigos com temática semelhante.

Para a pesquisa, realizaram-se os seguintes cruzamentos: Relacionamento Amoroso (Romantic relationship) or Término do Relacionamento Amoroso (Romantic Relationship Breakup) and Angústia Psicológica (Psychological Distress) or Sintomas Psicológicos (Psychological Symptoms) or Comportamento (Behavior).

O levantamento da amostra para a realização desse estudo foi realizado nas bases de dados Pubmed/Medline, BVS/Lilacs, Scielo, Pepsic e Google Acadêmico, no período de maio e junho de 2021.

A amostra de estudos selecionados para a presente revisão deu-se por meio dos seguintes critérios de inclusão: artigos originais; artigos de revisão; ensaios teóricos; relatos de experiência; ensaios clínicos e artigos publicados nos últimos 15 anos, sem restrição quanto à língua. Como critérios de exclusão, optou-se por excluir: livros; monografias; teses; dissertações; resenhas de livros, bem como artigos sem clareza; portanto, artigos que não apresentavam objetivo ou conclusão de maneira clara. 
O processo de seleção dos estudos foi dividido em três etapas. Na primeira, o processo de busca inicial, foram encontrados 157 artigos no total. Após isso, na segunda etapa, 112 estudos foram excluídos após a leitura dos títulos e resumos, sendo descartados aqueles que não se encontravam em acordo com os critérios de inclusão. Portanto, 45 artigos foram considerados elegíveis para a terceira etapa, a leitura completa dos estudos.

Por fim, os 45 estudos foram lidos integralmente, sendo excluídos 13 após uma breve análise da qualidade metodológica dos estudos e da adequação ao objetivo proposto. Assim, 32 artigos foram elegidos para a amostra final do estudo. Todo esse processo foi resumido na Tabela 1.

Tabela 1. Demonstrativos das categorias elencadas por base de dados.

\begin{tabular}{lcccc}
\hline Base de Dados & $\begin{array}{c}\text { Artigos } \\
\text { Recuperados }\end{array}$ & $\begin{array}{c}\mathbf{1}^{\text {a }} \text { Etapa (Leitura dos títulos } \\
\text { e resumos) }\end{array}$ & $\begin{array}{c}\mathbf{2}^{\text {a }} \text { Etapa (Leitura completa } \\
\text { dos artigos) }\end{array}$ & $\begin{array}{c}\text { Total de artigos } \\
\text { inseridos }\end{array}$ \\
\hline PubMED/Medline & 16 & 3 & 2 & \\
BVS/Lilacs & 28 & 7 & 3 & 32 \\
SciELO & 9 & 4 & 1 & \\
PepsiC & 5 & 2 & 19 & \\
Google & 99 & 29 & 32 & \\
Acadêmico & & &
\end{tabular}

Essa revisão foi constituída de 32 publicações (Quadro 1) acerca das implicações psicológicas e comportamentais apresentadas após o término de um relacionamento amoroso.

O enfoque das publicações coletadas que corroboram para o objetivo do artigo destaca alterações a níveis psicológico e comportamental. Sobre as alterações a nível psicológico, podemos compreendê-las de duas formas: negativas e positivas. Na primeira, destacaram-se ansiedade, depressão, angústia, raiva, tristeza, luto, baixa autoestima e a sensação de desamparo. Já a segunda, alívio, memórias positivas, sentimento de liberdade. No nível comportamental, comportamentos de perseguição, provocação e criminosos foram os principais encontrados.

Referindo-se a outras alterações menos delineadas, também foram encontradas: alterações na memória, frustração sexual, alterações neurológicas, desregulação emocional e sexo de separação.

Quadro 1. Resultados da pesquisa bibliográfica.

\begin{tabular}{|c|c|c|c|c|c|}
\hline $\mathrm{N}^{\circ}$ & AUTORES & TÍTULO & INDEXADOR & PERIODICO & ANO \\
\hline 1 & Barutcu e Aydin & $\begin{array}{l}\text { The Scale for Emotional Reactions } \\
\text { Following the Breakup }\end{array}$ & $\begin{array}{c}\text { GOOGLE } \\
\text { ACADÊMICO }\end{array}$ & $\begin{array}{l}\text { Procedia - Social and } \\
\text { Behavioral Sciences }\end{array}$ & 2013 \\
\hline 2 & Bastos, Rocha e De Almeida & $\begin{array}{l}\text { The effects of the breakup a loving } \\
\text { relationship in university students }\end{array}$ & SCIELO & Psicologia, Saúde \& Doenças & 2019 \\
\hline 3 & Bielski e Zordan & $\begin{array}{c}\text { Sentimentos predominantes, após o } \\
\text { término do relacionamento amoroso, no } \\
\text { início da adultez jovem }\end{array}$ & $\begin{array}{l}\text { GOOGLE } \\
\text { ACADÊMICO }\end{array}$ & Perspectiva, Erechim & 2014 \\
\hline 4 & Borges e Dell'Aglio & $\begin{array}{l}\text { Stalking Following the Breakup of Dating } \\
\text { Relationships in Adolescence }\end{array}$ & $\begin{array}{c}\text { GOOGLE } \\
\text { ACADÊMICO }\end{array}$ & Trends in Psychology & 2019 \\
\hline 5 & Brenner e Vogel & $\begin{array}{l}\text { Measuring Thought Content Valence } \\
\text { After a Breakup: Development of the } \\
\text { Positive and Negative Ex-Relationship } \\
\text { Thoughts (PANERT) Scale }\end{array}$ & $\begin{array}{l}\text { GOOGLE } \\
\text { ACADÊMICO }\end{array}$ & $\begin{array}{l}\text { Journal of Counseling } \\
\text { Psychology }\end{array}$ & 2015 \\
\hline 6 & $\begin{array}{c}\text { Bronfman, Ladd- } \\
\text { Luthringshauser, Goodman e } \\
\text { Sockol } \\
\end{array}$ & $\begin{array}{l}\text { Predictors of Breakup Distress Among } \\
\text { Residential College Students }\end{array}$ & $\begin{array}{l}\text { GOOGLE } \\
\text { ACADÊMICO }\end{array}$ & \begin{tabular}{|c|} 
College Student Affairs \\
Journal Southrn Association \\
for College Student Affairs \\
\end{tabular} & 2016 \\
\hline 7 & Carter, Knox e Hall & $\begin{array}{l}\text { Romantic Breakup: Difficult Loss for } \\
\text { Some but Not for Others }\end{array}$ & $\begin{array}{c}\text { GOOGLE } \\
\text { ACADÊMICO }\end{array}$ & Journal of Loss and Trauma & 2018 \\
\hline 8 & De Smet, Loeys, e Buysse & $\begin{array}{c}\text { Post-Breakup Unwanted Pursuit: A } \\
\text { Refined Analysis of the Role of Romantic } \\
\text { Relationship Charactierstics }\end{array}$ & $\begin{array}{l}\text { GOOGLE } \\
\text { ACADÊMICO }\end{array}$ & Journal of Family Violence & 2012 \\
\hline 9 & $\begin{array}{l}\text { De Smet, Uzieblo, Loeys, } \\
\text { Buysse e Onraedt }\end{array}$ & $\begin{array}{c}\text { Unwanted Pursuit Behavior After } \\
\text { Breakup: Occurrence, Risk Factors, and } \\
\text { Gender Differences }\end{array}$ & $\begin{array}{c}\text { GOOGLE } \\
\text { ACADÊMICO }\end{array}$ & Journal of Family Violence & 2015 \\
\hline 10 & $\begin{array}{c}\text { Del Palacio-González, Clark e } \\
\text { O'Sullivan }\end{array}$ & $\begin{array}{c}\text { Distress Severity Following a Romantic } \\
\text { Breakup Is Associated With Positive } \\
\text { Relationship Memories Among Emerging } \\
\text { Adults }\end{array}$ & $\begin{array}{c}\text { GOOGLE } \\
\text { ACADÊMICO }\end{array}$ & Emerging Adulthood & 2017 \\
\hline 11 & $\begin{array}{c}\text { Del Palacio-González, Clark e } \\
\text { O'Sullivan }\end{array}$ & $\begin{array}{l}\text { Cognitive processing in the aftermath of } \\
\text { relationship dissolution: Associations }\end{array}$ & BVS & Stress Health & 2017 \\
\hline
\end{tabular}




\begin{tabular}{|c|c|c|c|c|c|}
\hline & & $\begin{array}{c}\text { with concurrent and prospective distress } \\
\text { and posttraumatic growth. }\end{array}$ & & & \\
\hline 12 & DeLecce e Weisfeld & $\begin{array}{l}\text { An Evolutionary Explanation for Sex } \\
\text { Differences in Nonmarital Breakup } \\
\text { Experiences }\end{array}$ & $\begin{array}{l}\text { GOOGLE } \\
\text { ACADÊMICO }\end{array}$ & $\begin{array}{l}\text { Adaptive Human Behavior } \\
\text { and Physiology }\end{array}$ & 2016 \\
\hline 13 & Dooley, Fitzgerald e Giollabhui & $\begin{array}{c}\text { The risk and protective factors associated } \\
\text { with depression and anxiety in a national } \\
\text { sample of Irish adolescents. }\end{array}$ & BVS & $\begin{array}{c}\text { Irish journal of psychological } \\
\text { medicine }\end{array}$ & 2015 \\
\hline 14 & $\begin{array}{l}\text { Fisher, Brown, Aron, Strong e } \\
\text { Mashek }\end{array}$ & $\begin{array}{c}\text { Reward, Addiction, and Emotion } \\
\text { Regulation Systems Associated With } \\
\text { Rejection in Love }\end{array}$ & PUBMED & Journal of neurophysiology & 2010 \\
\hline 15 & $\begin{array}{c}\text { Francoeur, Lecomte, } \\
\begin{array}{c}\text { Daigneault, Brassard, Lecours } \\
\text { e Hache-Labelle }\end{array}\end{array}$ & $\begin{array}{c}\text { Social Cognition as Mediator of Romantic } \\
\text { Breakup Adjustment in Young Adults } \\
\text { Who Experienced Childhood } \\
\text { Maltreatment }\end{array}$ & $\begin{array}{l}\text { GOOGLE } \\
\text { ACADÊMICO }\end{array}$ & $\begin{array}{l}\text { Journal of Aggression, } \\
\text { Maltreatment \& Trauma }\end{array}$ & 2020 \\
\hline 16 & $\begin{array}{c}\text { Garabito, García, Neira e } \\
\text { Puentes }\end{array}$ & \begin{tabular}{|} 
Ruptura de pareja en adultos jóvenes y \\
salud mental: estrategias de \\
afrontamiento ante el estrés del término \\
de una relación \\
\end{tabular} & SCIELO & Psychologia & 2020 \\
\hline 17 & García e Ilabaca & $\begin{array}{c}\text { Ruptura de pareja, afrontamiento y } \\
\text { bienestar psicológico en adultos jóvenes }\end{array}$ & SCIELO & \begin{tabular}{|c|} 
Ajayu Órgano de Difusión \\
Científica del Departamento \\
de Psicología UCBSP
\end{tabular} & 2013 \\
\hline 18 & Gillbert e Sifers & $\begin{array}{c}\text { Bouncing Back from a Breakup: } \\
\text { Attachment, Time Perspective, Mental } \\
\text { Health, and Romantic Loss }\end{array}$ & $\begin{array}{c}\text { GOOGLE } \\
\text { ACADÊMICO }\end{array}$ & $\begin{array}{c}\text { Journal of College Student } \\
\text { Psychotherapy }\end{array}$ & 2011 \\
\hline 19 & Harvey e Karpinski & $\begin{array}{c}\text { The impact of social constraints on } \\
\text { adjustment following a romantic breakup }\end{array}$ & $\begin{array}{c}\text { GOOGLE } \\
\text { ACADÊMICO } \\
\end{array}$ & Personal Relationships & 2016 \\
\hline 20 & Larson, Sweeten e Piquero & $\begin{array}{c}\text { With or Without You? Contextualizing } \\
\text { the Impact of Romantic Relationship } \\
\text { Breakup on Crime Among Serious } \\
\text { Adolescent Offenders. }\end{array}$ & BVS & $\begin{array}{l}\text { Journal of youth and } \\
\text { adolescence }\end{array}$ & 2016 \\
\hline 21 & Lopez-Cantero, P. & $\begin{array}{l}\text { The Break-Up Check: Exploring Romantic } \\
\text { Love through Relationship Terminations. }\end{array}$ & BVS & Philosophia & 2018 \\
\hline 22 & $\begin{array}{l}\text { Love, Nalbone, Hecker, } \\
\text { Sweeney e Dharnidharka }\end{array}$ & $\begin{array}{c}\text { Suicidal Risk Following the Termination } \\
\text { of Romantic Relationships. }\end{array}$ & BVS & Crisis & 2018 \\
\hline 23 & Luciano e Orth & $\begin{array}{c}\text { Transitions in romantic relationships and } \\
\text { development of self-esteem. }\end{array}$ & BVS & $\begin{array}{l}\text { Journal of personality and } \\
\text { social psychology }\end{array}$ & 2017 \\
\hline 24 & Marcondes, Trierweiler e Cruz & $\begin{array}{c}\text { Sentimentos predominantes após o } \\
\text { término de um relacionamento amoroso }\end{array}$ & PEPSIC & $\begin{array}{l}\text { Psicologia: ciência e } \\
\text { profissão }\end{array}$ & 2006 \\
\hline 25 & $\begin{array}{c}\text { Mason, Law, Bryan, Portley e } \\
\text { Sbarra }\end{array}$ & \begin{tabular}{|c|} 
Facing a breakup: Electromyographic \\
responses moderate self-concept recovery \\
following a romantic separation
\end{tabular} & $\begin{array}{l}\text { GOOGLE } \\
\text { ACADÊMICO }\end{array}$ & Personal Relationships & 2012 \\
\hline 26 & Moran, Wade e Murray & $\begin{array}{c}\text { The psychology of breakup sex: Exploring } \\
\text { the motivational factors and affective } \\
\text { consequences of post-breakup sexual } \\
\text { activity }\end{array}$ & $\begin{array}{l}\text { GOOGLE } \\
\text { ACADÊMICO }\end{array}$ & Evolutionary Psychology & 2020 \\
\hline 27 & $\begin{array}{c}\text { Moroz, Chen, Daljeet e } \\
\text { Campbell } \\
\end{array}$ & The Dark Triad and break-up distress & $\begin{array}{c}\text { GOOGLE } \\
\text { ACADÊMICO }\end{array}$ & $\begin{array}{c}\text { Personality and Individual } \\
\text { Differences } \\
\end{array}$ & 2018 \\
\hline 28 & $\begin{array}{l}\text { Norona, Scharf, Welsh e } \\
\text { Shulman }\end{array}$ & $\begin{array}{c}\text { Predicting post-breakup distress and } \\
\text { growth in emerging adulthood: The roles } \\
\text { of relationship satisfaction and emotion } \\
\text { regulation }\end{array}$ & $\begin{array}{c}\text { GOOGLE } \\
\text { ACADÊMICO }\end{array}$ & Journal of Adolescence & 2018 \\
\hline 29 & Rosa, Valente e Oliveira. & $\begin{array}{l}\text { A vivência do luto em decorrência do } \\
\text { término de relacionamentos amorosos }\end{array}$ & $\begin{array}{c}\text { GOOGLE } \\
\text { ACADÊMICO }\end{array}$ & $\begin{array}{l}\text { Estudos: Revista de ciencias } \\
\text { humanas e sociais aplicadas }\end{array}$ & 2013 \\
\hline 30 & Samios, Henson e Simpson. & $\begin{array}{c}\text { Benefit Finding and Psychological } \\
\text { Adjustment Following a Non-Marital } \\
\text { Relationship Breakup }\end{array}$ & $\begin{array}{l}\text { GOOGLE } \\
\text { ACADÊMICO }\end{array}$ & $\begin{array}{l}\text { Journal of Relationships } \\
\text { Research }\end{array}$ & 2014 \\
\hline 31 & $\begin{array}{c}\text { Verhallen, Renken, Marsman e } \\
\text { Ter Horst }\end{array}$ & $\begin{array}{l}\text { Romantic relationship breakup: An } \\
\text { experimental model to study effects of } \\
\text { stress on depression (-like) symptoms. }\end{array}$ & BVS & PLoS One & 2019 \\
\hline 32 & $\begin{array}{c}\text { Verhallen, Renken, Marsman e } \\
\text { Ter Horst }\end{array}$ & $\begin{array}{l}\text { Working Memory Alterations After a } \\
\text { Romantic Relationship Breakup }\end{array}$ & PUBMED & $\begin{array}{l}\text { Frontiers in Behavioral } \\
\text { Neuroscience }\end{array}$ & 2021 \\
\hline
\end{tabular}

Embora os artigos coletados para a realização dessa revisão já estejam apresentados no Quadro 1, no Quadro 2 foi apresentado um maior detalhamento dessa amostra de artigos com objetivo de tornar o mais transparente possível quais artigos foram selecionados. 
Quadro 2. Transparência da amostra de estudos.

\begin{tabular}{|c|c|c|c|c|}
\hline TÍTULO & OBJETIVO & MÉTODO & CONCLUSÃO & POPULAÇÃO \\
\hline $\begin{array}{c}\text { The Scale for Emotional } \\
\text { Reactions Following the } \\
\text { Breakup }\end{array}$ & $\begin{array}{c}\text { O objetivo deste estudo foi } \\
\text { desenvolver e validar uma escala que } \\
\text { mede as reações emocionais após o } \\
\text { rompimento de um relacionamento } \\
\text { não conjugal. }\end{array}$ & $\begin{array}{c}\text { Uma escala de } 20 \text { itens foi } \\
\text { desenvolvida e aplicada a } \\
\text { uma amostra. }\end{array}$ & $\begin{array}{l}\text { Os resultados da Análise } \\
\text { Fatorial Exploratória } \\
\text { indicaram uma estrutura } \\
\text { de dois fatores e esses } \\
\text { fatores foram nomeados } \\
\text { como emoções emanadas } \\
\text { de si mesmo e emoções } \\
\text { emanadas do parceiro. } \\
\end{array}$ & $\begin{array}{l}\text { Amostra de } 101 \text { universitários que } \\
\text { romperam seu relacionamento nos } \\
\text { últimos dois anos. }\end{array}$ \\
\hline $\begin{array}{l}\text { The effects of the } \\
\text { breakup a loving } \\
\text { relationship in } \\
\text { university students }\end{array}$ & $\begin{array}{c}\text { A ruptura de um relacionamento } \\
\text { amoroso é uma experiência comum } \\
\text { em estudantes universitários; } \\
\text { entretanto, para alguns desses jovens, } \\
\text { esse evento pode criar emoções muito } \\
\text { estressantes e angustiantes, exigindo } \\
\text { muito das competências emocionais. }\end{array}$ & \begin{tabular}{|} 
Foi utilizada uma \\
metodologia quantitativa \\
por meio da aplicação de \\
quatro instrumentos já \\
utilizados em outras \\
pesquisas.
\end{tabular} & \begin{tabular}{|} 
Os resultados permitiram \\
detectar a existência de \\
sintomas de Luto \\
Prolongado, Traumático e \\
Amargura nesses jovens, \\
após a perda de um \\
relacionamento amoroso, \\
bem como a relevância das \\
Dificuldades de Regulação \\
Emocional na predição dos \\
sintomas de Luto \\
Prolongado, Traumático e \\
Amargura.
\end{tabular} & $\begin{array}{l}\text { Este estudo envolveu } 100 \\
\text { estudantes universitários com idade } \\
\text { entre } 18 \text { e } 36 \text { anos e que } \\
\text { vivenciaram pelo menos uma perda } \\
\text { de um relacionamento amoroso. }\end{array}$ \\
\hline \begin{tabular}{|} 
Sentimentos \\
predominantes, após o \\
término do \\
relacionamento \\
amoroso, no início da \\
adultez jovem
\end{tabular} & $\begin{array}{c}\text { Este estudo teve como objetivo } \\
\text { compreender a vivência de adultos } \\
\text { jovens ao término do relacionamento } \\
\text { amoroso. }\end{array}$ & $\begin{array}{c}\text { O instrumento utilizado } \\
\text { foi a Escala de Vivência de } \\
\text { Sentimentos Após o } \\
\text { Término de } \\
\text { Relacionamentos Afetivos, } \\
\text { analisada segundo as } \\
\text { instruções de seus autores. }\end{array}$ & $\begin{array}{c}\text { Conclui-se que a ênfase } \\
\text { nos sentimentos positivos } \\
\text { está relacionada a aspectos } \\
\text { individuais, do estágio de } \\
\text { vida e contextuais. }\end{array}$ & $\begin{array}{c}\text { Participaram } 30 \text { indivíduos: } 13 \\
\text { homens e } 17 \text { mulheres, entre } 20 \text { e } \\
25 \text { anos, residentes em Erechim. }\end{array}$ \\
\hline $\begin{array}{l}\text { Stalking Following the } \\
\text { Breakup of Dating } \\
\text { Relationships in } \\
\text { Adolescence }\end{array}$ & $\begin{array}{c}\text { Este estudo transversal e exploratório } \\
\text { investigou a presença de stalking, no } \\
\text { período pós-ruptura de } \\
\text { relacionamentos afetivo-sexuais de } \\
\text { adolescentes. }\end{array}$ & \begin{tabular}{|c|} 
Administramos uma \\
versão adaptada do \\
Stalking Behavior \\
Inventory - Versão II, que \\
avalia a prevalência de \\
stalking behaviors em uma \\
população adulta após o \\
rompimento de um \\
relacionamento íntimo.
\end{tabular} & \begin{tabular}{|} 
Destaca-se a necessidade \\
de melhor compreensão do \\
fenômeno do stalking, \\
assim como de políticas \\
públicas de intervenção e \\
prevenção, uma vez que \\
tanto vítimas quanto \\
perpetradores necessitam \\
de atendimento \\
psicológico, a fim de \\
romper o ciclo de violência \\
no namoro.
\end{tabular} & $\begin{array}{l}\text { O presente estudo transversal } \\
\text { exploratório contou com a } \\
\text { participação de } 527 \text { adolescentes } \\
\text { entre 14 e 19anos, alunos de dez } \\
\text { escolas de ensino médio públicas e } \\
\text { privadas da região metropolitana de } \\
\text { Porto Alegre (Rio Grande do Sul, } \\
\text { Brasil), selecionados. por meio de } \\
\text { amostragem de conveniência. }\end{array}$ \\
\hline \begin{tabular}{|} 
Measuring Thought \\
Content Valence After a \\
Breakup: Development \\
of the Positive and \\
Negative Ex- \\
Relationship Thoughts \\
(PANERT) Scale
\end{tabular} & \begin{tabular}{|} 
O fim de um relacionamento amoroso \\
é uma preocupação comum e séria \\
entre os clientes dos centros de \\
aconselhamento universitários. Os \\
pesquisadores destacaram a \\
necessidade de compreender a \\
natureza dos pensamentos sobre um \\
ex-relacionamento, porque eles \\
podem levar a intervenções clínicas \\
únicas.
\end{tabular} & $\begin{array}{l}\text { Escala de pensamentos ex- } \\
\text { relacionamentos positivos } \\
\text { e negativos de } 12 \text { itens } \\
\text { (PANERT) em } 4 \text { amostras. }\end{array}$ & \begin{tabular}{|c} 
A direção dessas relações \\
sugere que a valência de \\
conteúdo de pensamento \\
positivo pode ser \\
consistentemente mal- \\
adaptativa à recuperação \\
de um ex-relacionamento, \\
e a valência de conteúdo \\
de pensamento negativo \\
pode ter características \\
maladaptativas e \\
adaptativas. Implicações \\
para pesquisas e práticas \\
futuras são discutidas.
\end{tabular} & $\begin{array}{l}4 \text { amostras. Amostra } 1(n=275) \text {, } \\
\text { amostra } 2(n=509), \text { amostra } 3 \\
(n=291), \text { amostra } 4(n=133) .\end{array}$ \\
\hline $\begin{array}{l}\text { Predictors of Breakup } \\
\text { Distress Among } \\
\text { Residential College } \\
\text { Students }\end{array}$ & $\begin{array}{c}\text { Este estudo avaliou preditores de } \\
\text { sofrimento após separações entre } \\
\text { alunos matriculados em uma pequena } \\
\text { faculdade residencial de artes liberais. }\end{array}$ & $\begin{array}{c}\text { Os participantes então } \\
\text { completaram a Break-up } \\
\text { Distress Scale (BDS), uma } \\
\text { escala de } 16 \text { itens que } \\
\text { avalia a angústia } \\
\text { relacionada ao término de } \\
\text { relacionamentos } \\
\text { amorosos. }\end{array}$ & \begin{tabular}{|c|} 
Como desenvolver \\
relacionamentos íntimos é \\
um desafio fundamental \\
no início da vida adulta, é \\
importante compreender \\
os fatores relacionados à \\
experiência de sofrimento \\
emocional quando os \\
relacionamentos \\
românticos terminam.
\end{tabular} & $\begin{array}{l}100 \text { participantes no total final. } \\
\text { Aproximadamente dois terços da } \\
\text { amostra eram mulheres ( } \mathrm{n}=69) \text {, } \\
\text { enquanto } 31 \% \text { eram homens. }\end{array}$ \\
\hline $\begin{array}{l}\text { Romantic Breakup: } \\
\text { Difficult Loss for Some } \\
\text { but Not for Others }\end{array}$ & $\begin{array}{l}\text { Identificou fatores associados a } \\
\text { resultados positivos (sentir-se feliz, } \\
\text { menos ansioso, sensação de alívio, } \\
\text { liberdade) e negativos (tristeza, } \\
\text { ciúme, perda de autoestima, } \\
\text { ansiedade) após um rompimento } \\
\text { romântico ou perda. }\end{array}$ & Uma pesquisa de 32 itens. & \begin{tabular}{|c|} 
Análise revelou \\
associações complexas, \\
mas, em geral, ser mulher, \\
negro, iniciador da \\
separação e heterossexual \\
tinham maior \\
probabilidade de estar \\
associados a resultados \\
positivos. As análises \\
multivariadas sugeriram \\
que ser o iniciador do
\end{tabular} & 286 alunos de graduação. \\
\hline
\end{tabular}




\begin{tabular}{|c|c|c|c|c|}
\hline & & & \begin{tabular}{|c|} 
rompimento foi um \\
preditor chave de \\
resultados mais favoráveis \\
ao rompimento.
\end{tabular} & \\
\hline $\begin{array}{c}\text { Post-Breakup Unwanted } \\
\text { Pursuit: A Refined } \\
\text { Analysis of the Role of } \\
\text { Romantic Relationship } \\
\text { Characteristics }\end{array}$ & $\begin{array}{c}\text { Este estudo reexaminou o papel das } \\
\text { características do relacionamento } \\
\text { romântico na perpetração do } \\
\text { comportamento indesejado de } \\
\text { perseguição (UPB). }\end{array}$ & Frequência de Baps. & \begin{tabular}{|c|} 
As análises do moderador \\
revelaram efeitos \\
significativos de satisfação \\
no relacionamento, \\
alternativas, \\
investimentos e apego \\
ansioso em interação com \\
o status de iniciador e de \\
alternativas de \\
relacionamento em \\
interação com afeto \\
negativo pós-rompimento. \\
\end{tabular} & $\begin{array}{l}\text { As características de } \\
\text { relacionamento foram investigadas } \\
\text { levando em conta o papel das } \\
\text { características de rompimento } \\
\text { usando dados de } 396 \text { adultos } \\
\text { divorciados e regressões de } \\
\text { contagem avançada. }\end{array}$ \\
\hline \begin{tabular}{|c|} 
Unwanted Pursuit \\
Behavior After Breakup: \\
Occurrence, Risk \\
Factors, and Gender \\
Differences
\end{tabular} & \begin{tabular}{|c|} 
O presente estudo teve dois objetivos \\
principais. Em primeiro lugar, ao lado \\
de registrar a ocorrência de BUPs em \\
ex-parceiros adultos, objetivamos \\
estender a pesquisa explicativa sobre \\
a perpetração da UPB pós separação \\
por meio de uma abordagem \\
integrativa. Especificamente em linha \\
com a ideia de que stalking e UPB são \\
determinados por fatores de risco em \\
diferentes níveis-nosso objetivo era \\
realizar um exame integrado dos \\
fatores de risco no nível do \\
rompimento, relacionamento pré- \\
rompimento, bem como do \\
perpetrador individual identificado \\
em pesquisas anteriores. Em segundo \\
lugar, nosso objetivo foi examinar as \\
diferenças entre ex-parceiros do sexo \\
masculino e feminino e ex-parceiros \\
do mesmo sexo e de sexo oposto em \\
nossa avaliação da ocorrência e \\
fatores de risco de perpetração de \\
UPB. \\
\end{tabular} & \begin{tabular}{|c} 
Todos os canais de \\
recrutamento promoveram \\
nosso site, onde os \\
participantes poderiam \\
preencher uma série de \\
questionários. Isso \\
resultou em uma amostra \\
de conveniência de 906 \\
participantes, dos quais \\
631 \\
(69,6\%) completaram \\
totalmente a avaliação \\
online de forma válida. Os \\
entrevistados foram \\
solicitados a responder à \\
pesquisa durante uma \\
sessão online, que levou \\
em média menos de uma \\
hora.
\end{tabular} & $\begin{array}{c}\text { O número de UPBs } \\
\text { perpetrados foi explicado } \\
\text { pelas características do } \\
\text { rompimento (iniciação do } \\
\text { ex-parceiro do } \\
\text { rompimento e ruminação } \\
\text { ou preocupação cognitiva } \\
\text { com o ex-parceiro), } \\
\text { características do } \\
\text { relacionamento (apego } \\
\text { ansioso no relacionamento } \\
\text { anterior), e características } \\
\text { individuais do perpetrador } \\
\text { (traços limítrofes e } \\
\text { comportamentos } \\
\text { delinquentes anteriores). }\end{array}$ & $\begin{array}{l}\text { Homens e mulheres com mais de } 18 \\
\text { anos que romperam com parceiro } \\
\text { romântico do mesmo sexo ou do } \\
\text { sexo oposto nos últimos } 2 \text { anos } \\
\text { foram convidados a participar do } \\
\text { estudo. } \\
\text { Os } 631 \text { participantes ( } 64,3 \% \\
\text { mulheres; } 98,1 \% \text { de nacionalidade } \\
\text { belga) tinham em média } 30,57 \text { anos } \\
\text { (SD }=10,75 \text {, intervalo: } 18-61 .\end{array}$ \\
\hline \begin{tabular}{|c|} 
Distress Severity \\
Following a Romantic \\
Breakup Is Associated \\
With Positive \\
Relationship Memories \\
Among Emerging Adults
\end{tabular} & $\begin{array}{c}\text { Examinar as ligações entre angústia } \\
\text { específica do rompimento, sintomas } \\
\text { depressivos e memórias de } \\
\text { relacionamento de diferentes } \\
\text { valências. }\end{array}$ & \begin{tabular}{|} 
Noventa e um adultos \\
emergentes que \\
experimentaram um \\
rompimento romântico \\
recente registraram a \\
frequência de memórias de \\
relacionamento \\
espontâneas positivas e \\
negativas em um diário de \\
memória online de quatro \\
dias. \\
\end{tabular} & $\begin{array}{c}\text { Os resultados sugerem que } \\
\text { experiências de memórias } \\
\text { positivas são críticas para } \\
\text { a compreensão do grau de } \\
\text { angústia que um jovem } \\
\text { pode sentir após um } \\
\text { rompimento. }\end{array}$ & 91 adultos. \\
\hline $\begin{array}{c}\text { Cognitive processing in } \\
\text { the aftermath of } \\
\text { relationship dissolution: } \\
\text { Associations with } \\
\text { concurrent and } \\
\text { prospective distress and } \\
\text { posttraumatic growth. }\end{array}$ & $\begin{array}{c}\text { A dissolução do relacionamento } \\
\text { amoroso não conjugal está entre os } \\
\text { eventos mais estressantes vividos por } \\
\text { jovens adultos. No entanto, alguns } \\
\text { indivíduos apresentam crescimento } \\
\text { pós-traumático após a dissolução do } \\
\text { relacionamento. Pouco se sabe sobre a } \\
\text { contribuição específica e diferencial } \\
\text { dos estilos de processamento } \\
\text { cognitivo do tipo traço específico do } \\
\text { evento para cada um desses } \\
\text { resultados. }\end{array}$ & \begin{tabular}{|c|} 
Um projeto longitudinal \\
foi empregado no qual \\
processamento cognitivo \\
tipo traço (reflexão e \\
reflexão) e específico de \\
dissolução (intrusivo e \\
deliberado) foi examinado \\
como preditores de \\
crescimento (Inventário de \\
crescimento pós- \\
traumático) e angústia \\
(Breakup Distress Scale) \\
após uma recente \\
dissolução de \\
relacionamento.
\end{tabular} & \begin{tabular}{|} 
Pensar deliberadamente \\
na dissolução estava \\
relacionado a resultados \\
psicológicos positivos. Em \\
contraste, cognições de \\
dissolução intrusivas e \\
uma tendência para chocar \\
tiveram uma associação \\
mista (paradoxal) com \\
ajustamento psicológico.
\end{tabular} & 148 participantes. \\
\hline $\begin{array}{l}\text { An Evolutionary } \\
\text { Explanation for Sex } \\
\text { Differences in } \\
\text { Nonmarital Breakup } \\
\text { Experiences }\end{array}$ & $\begin{array}{c}\text { Expandir a esparsa literatura existente } \\
\text { sobre dissolução de relacionamento } \\
\text { não-matrimonial de uma perspectiva } \\
\text { evolutiva para investigar como as } \\
\text { diferenças de sexo nas estratégias de } \\
\text { acasalamento afetam os processos de } \\
\text { separação, como o período de } \\
\text { enfrentamento, emoções vivenciadas } \\
\text { e comportamentos pós-término. } \\
\end{array}$ & \begin{tabular}{c|} 
Dados de autorrelato \\
coletados por meio o \\
Mechanical Turk.
\end{tabular} & $\begin{array}{c}\text { No geral, essas descobertas } \\
\text { apóiam o dimorfismo } \\
\text { sexual no valor do humor e } \\
\text { maior escolha feminina, } \\
\text { mesmo após a seleção } \\
\text { inicial do parceiro. }\end{array}$ & 392 participantes \\
\hline
\end{tabular}




\begin{tabular}{|c|c|c|c|c|}
\hline $\begin{array}{l}\text { The risk and protective } \\
\text { factors associated with } \\
\text { depression and anxiety } \\
\text { in a national sample of } \\
\text { Irish adolescents. }\end{array}$ & $\begin{array}{c}\text { O objetivo deste estudo é examinar os } \\
\text { fatores de risco e proteção associados } \\
\text { à ansiedade e depressão em uma } \\
\text { amostra representativa de } \\
\text { adolescentes irlandeses. }\end{array}$ & \begin{tabular}{|c} 
Os dados usados neste \\
estudo foram retirados de \\
um subconjunto do My \\
World Survey (MWS). O \\
subconjunto MWS-Second \\
Level (MWS-SL) consiste \\
em uma amostra aleatória \\
de 72 escolas. As medidas \\
de resultado foram \\
depressão e ansiedade. Os \\
fatores de risco e proteção \\
incluíram medidas nos \\
domínios \\
sociodemográfico, \\
psicossocial e de assunção \\
de risco.
\end{tabular} & \begin{tabular}{|c} 
Como os fatores que \\
protegem e colocam os \\
adolescentes em risco de \\
ansiedade e depressão \\
existem em todos os níveis \\
do sistema ecológico do \\
adolescente, o estudo \\
apóia uma abordagem \\
baseada na comunidade \\
para a saúde mental dos \\
jovens.
\end{tabular} & $\begin{array}{c}\text { Amostra aleatória de } 72 \text { escolas, } \\
\text { com uma amostra final de } 6085 \\
\text { alunos }\end{array}$ \\
\hline $\begin{array}{l}\text { Reward, Addiction, and } \\
\text { Emotion Regulation } \\
\text { Systems Associated } \\
\text { With Rejection in Love }\end{array}$ & $\begin{array}{c}\text { A rejeição romântica causa uma } \\
\text { profunda sensação de perda e afeto } \\
\text { negativo. Pode induzir depressão } \\
\text { clínica e, em casos extremos, levar ao } \\
\text { suicídio e / ou homicídio. }\end{array}$ & \begin{tabular}{|} 
Para identificar os \\
sistemas neurais \\
associados a esse estado \\
de perda natural, usamos a \\
ressonância magnética \\
funcional para estudar \\
participantes que haviam \\
sido rejeitados \\
recentemente por um \\
parceiro, mas relataram \\
que ainda estavam \\
intensamente \\
"apaixonados". Os \\
participantes \\
alternadamente viram \\
uma fotografia de sua \\
amada rejeitada e uma \\
fotografia de um familiar, \\
individual, intercalada \\
com uma tarefa de \\
distração-atenção.
\end{tabular} & \begin{tabular}{|} 
As ativações do cérebro \\
anterior associadas à \\
relevância motivacional, \\
ganho / perda, desejo por \\
cocaína, vício e regulação \\
emocional sugerem que \\
sistemas de ordem \\
superior sujeitos à \\
experiência e ao \\
aprendizado também \\
podem mediar a reação de \\
rejeição. Os resultados \\
mostram ativação de \\
sistemas de recompensa, \\
previamente identificados \\
por estímulos monetários, \\
em um estado de emoção \\
natural, endógeno e \\
negativo.
\end{tabular} & 10 mulheres e 5 homens \\
\hline $\begin{array}{l}\text { Social Cognition as } \\
\text { Mediator of Romantic } \\
\text { Breakup Adjustment in } \\
\text { Young Adults Who } \\
\text { Experienced Childhood } \\
\text { Maltreatment }\end{array}$ & $\begin{array}{c}\text { O presente estudo investigou se os } \\
\text { maus-tratos na infância e a cognição } \\
\text { social (regulação emocional, } \\
\text { mentalização, atribuições causais) } \\
\text { estão associados ao ajuste do } \\
\text { rompimento romântico na juventude } \\
\text { (resiliência, sintomas psiquiátricos, } \\
\text { angústia); e se a cognição social } \\
\text { medeia a relação entre maus-tratos na } \\
\text { infância e adaptação à separação } \\
\text { romântica. }\end{array}$ & $\begin{array}{c}\text { Maus-tratos na infância } \\
\text { Experiências de trauma na } \\
\text { infância foram avaliadas } \\
\text { usando o Childhood } \\
\text { Trauma Questionnaire } \\
\text { Short-form (CTQ-SF). A } \\
\text { versão francesa do } \\
\text { Questionário de Regulação } \\
\text { da Emoção Cognitiva } \\
\text { (CERQ)) foi usado para } \\
\text { avaliar a regulação } \\
\text { emocional. Mentalização } \\
\text { A mentalização foi medida } \\
\text { pela Escala de } \\
\text { Mentalização. Os itens } \\
\text { medem a mentalização } \\
\text { auto-relacionada, a } \\
\text { mentalização relacionada } \\
\text { a outros e a motivação } \\
\text { para mentalizar. }\end{array}$ & \begin{tabular}{|} 
Os resultados do presente \\
estudo confirmam que o \\
período pós-término de \\
um relacionamento \\
amoroso é um fator de \\
risco para a vitimização \\
por perseguição em \\
adolescentes, \\
principalmente quando \\
houve vitimização prévia \\
envolvendo violência física \\
e psicológica durante o \\
relacionamento.
\end{tabular} & $\begin{array}{l}483 \text { alunos da Faculdade de Artes e } \\
\text { Ciências de uma grande } \\
\text { universidade canadense que haviam } \\
\text { passado por uma separação nos } \\
\text { últimos três meses. }\end{array}$ \\
\hline $\begin{array}{l}\text { Ruptura de pareja en } \\
\text { adultos jóvenes y salud } \\
\text { mental: estrategias de } \\
\text { afrontamiento ante el } \\
\text { estrés del término de } \\
\text { una relación }\end{array}$ & $\begin{array}{c}\text { Estabelecer a relação entre estratégias } \\
\text { de enfrentamento, sintomas } \\
\text { depressivos e satisfação com a vida em } \\
\text { adultos jovens após um intervalo } \\
\text { amoroso. }\end{array}$ & $\begin{array}{l}\text { Foram aplicadas as escalas } \\
\text { Brief COPE de estratégias } \\
\text { de enfrentamento, SWLS } \\
\text { Life Satisfaction Scale, } \\
\text { CES-D Depression Scale do } \\
\text { Center for Epidemiological } \\
\text { Studies, ERQ Emotional } \\
\text { Regulation Questionnaire, } \\
\text { RRS Rumiative Response } \\
\text { Scale, somados a um } \\
\text { questionário } \\
\text { sociodemográfico.o, } \\
\text { sintomas depressivos e } \\
\text { satisfação com a vida em } \\
\text { adultos jovens após um } \\
\text { intervalo amoroso. }\end{array}$ & $\begin{array}{l}\text { É possível focar nas linhas } \\
\text { de ação para promover } \\
\text { respostas mais adaptativas } \\
\text { e modificar as respostas } \\
\text { menos adaptativas em } \\
\text { pessoas afetadas por um } \\
\text { colapso. }\end{array}$ & $\begin{array}{l}\text { Foram entrevistadas } 220 \text { pessoas, } \\
66,8 \% \text { mulheres, com idade entre } 18 \\
\text { e } 40 \text { anos. }\end{array}$ \\
\hline
\end{tabular}




\begin{tabular}{|c|c|c|c|c|}
\hline \begin{tabular}{|} 
Ruptura de pareja, \\
afrontamiento y \\
bienestar psicológico en \\
adultos jóvenes
\end{tabular} & $\begin{array}{c}\text { O objetivo deste estudo é analisar a } \\
\text { relação entre as estratégias de } \\
\text { enfrentamento utilizadas diante da } \\
\text { ruptura do relacionamento de um } \\
\text { casal e o bem-estar psicológico. }\end{array}$ & \begin{tabular}{|c|} 
As estratégias de \\
enfrentamento foram \\
avaliadas com o Coping \\
Strategies Inventory (CSI) \\
e o bem-estar psicológico \\
com Psychological Well- \\
Being Scales (PWBS) \\
adaptado por Diaz.
\end{tabular} & \begin{tabular}{|c|} 
Os resultados mostram \\
uma relação positiva entre \\
estratégias evitativas de \\
enfrentamento, busca de \\
suporte social e expressão \\
emocional com o bem- \\
estar psicológico, além \\
disso, existe uma relação \\
negativa da autocrítica e \\
do pensamento positivo \\
com a dimensão do bem- \\
estar denominada relações \\
positivas com os outros.
\end{tabular} & $\begin{array}{c}\text { Participaram } 227 \text { pessoas, homens e } \\
\text { mulheres, entre } 18 \text { e } 35 \text { anos } \\
\text { residentes na cidade de Concepcion, } \\
\text { Chile, e que haviam terminado um } \\
\text { relacionamento estável nos últimos } \\
\text { doze meses. } \\
\end{array}$ \\
\hline $\begin{array}{l}\text { Bouncing Back from a } \\
\text { Breakup: Attachment, } \\
\text { Time Perspective, } \\
\text { Mental Health, and } \\
\text { Romantic Loss }\end{array}$ & $\begin{array}{c}\text { Lidar com uma separação romântica é } \\
\text { uma tarefa normal de } \\
\text { desenvolvimento da idade adulta } \\
\text { emergente. Por causa de seu papel em } \\
\text { influenciar os relacionamentos } \\
\text { interpessoais e o ajuste, a história do } \\
\text { apego e as perspectivas temporais } \\
\text { podem influenciar a resiliência à } \\
\text { perda romântica. }\end{array}$ & \begin{tabular}{|c|} 
O anônimo enquete \\
incluído um demográfico \\
questionário, escrito pelos \\
pesquisadores para \\
retrospectivamente \\
avaliarem o sofrimento no \\
Tempo de rompimento, e \\
de outras variáveis \\
padronizadas, através de \\
instrumentos psicológicos \\
validados: the Parental \\
Bonding Instrument, a \\
short form of the \\
ZimbardoTime Perspective \\
Inventory, Future Time \\
Orientation Scale, and the \\
Mental Health Inventory.
\end{tabular} & $\begin{array}{c}\text { Resultados sugerem que os } \\
\text { profissionais que } \\
\text { aconselham estudantes } \\
\text { universitários em } \\
\text { separação podem } \\
\text { considerar abordar o } \\
\text { vínculo parental e a } \\
\text { orientação temporal. } \\
\end{array}$ & $\begin{array}{l}\text { Pesquisa online com } 1.404 \\
\text { estudantes universitários com } \\
\text { idades entre } 18 \text { e } 25 \text { anos. }\end{array}$ \\
\hline $\begin{array}{l}\text { The impact of social } \\
\text { constraints on } \\
\text { adjustment following a } \\
\text { romantic breakup }\end{array}$ & $\begin{array}{c}\text { Elucidar a compreensão da } \\
\text { recuperação das pessoas da dissolução } \\
\text { de relacionamentos românticos. }\end{array}$ & $\begin{array}{l}\text { Preenchimento de estudo } \\
\text { online. }\end{array}$ & \begin{tabular}{|c} 
Os resultados indicam que \\
as restrições sociais estão \\
associadas ao sofrimento \\
psicológico e são \\
susceptíveis de impactar a \\
recuperação de um \\
rompimento.
\end{tabular} & \begin{tabular}{|c|} 
Duzentos e trinta e oito alunos \\
completaram o estudo online. Dos \\
238 participantes, 21 indivíduos não \\
atenderam aos critérios de \\
elegibilidade detalhados abaixo e \\
foram posteriormente excluídos de \\
todas as análises, deixando uma \\
amostra final de 217 (140 mulheres, \\
Midade $=21,09$ anos). \\
\end{tabular} \\
\hline \begin{tabular}{|l} 
With or Without You? \\
Contextualizing the \\
Impact of Romantic \\
Relationship Breakup on \\
Crime Among Serious \\
Adolescent Offenders.
\end{tabular} & $\begin{array}{c}\text { Examinar os efeitos do rompimento } \\
\text { do relacionamento sobre o crime entre } \\
\text { os jovens envolvidos com a justiça - } \\
\text { um grupo importante com relevância } \\
\text { política. }\end{array}$ & \begin{tabular}{|c|} 
Referimo-nos aos dados do \\
Pathways to Desistance \\
Study, um estudo \\
longitudinal de 1354 (14\% \\
mulheres) jovens julgados \\
dos sistemas de tribunais \\
juvenis e adultos em \\
Phoenix e Filadélfia, para \\
avaliar a natureza e a \\
complexidade desta \\
associação. \\
\end{tabular} & \begin{tabular}{|c|} 
Concluímos com uma \\
discussão de nossas \\
descobertas, suas \\
implicações políticas e o \\
que elas significam para as \\
pesquisas sobre \\
relacionamentos e crimes \\
entre adolescentes \\
infratores graves que estão \\
avançando.
\end{tabular} & \begin{tabular}{|c} 
Jovens do sexo masculino $(\mathrm{n}=1170)$ \\
e do sexo feminino $(\mathrm{n}=184)$ em \\
grande parte afro-americanos ou \\
hispânicos $(74,9 \%)$ e foram julgados \\
na Filadélfia, Pensilvânia $(\mathrm{n}=700)$ \\
ou Phoenix, Arizona $(\mathrm{n}=654) .14 \mathrm{a}$ \\
17 anos quando cometeram o crime \\
ou a propriedade, arma ou \\
contravenção sexual grave de que \\
foram julgados. \\
Total: 1354 (14\% mulheres) jovens. \\
\end{tabular} \\
\hline $\begin{array}{l}\text { The Break-Up Check: } \\
\text { Exploring Romantic } \\
\text { Love through } \\
\text { Relationship } \\
\text { Terminations. }\end{array}$ & $\begin{array}{c}\text { Examinando o processo de luto que se } \\
\text { segue ao término de relacionamentos } \\
\text { não escolhidos. }\end{array}$ & 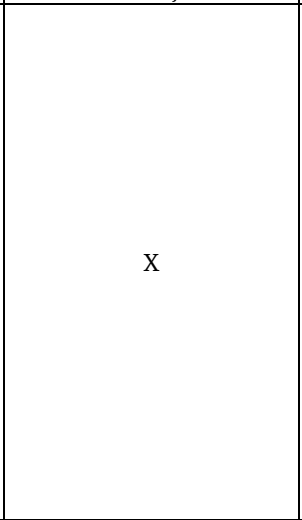 & $\begin{array}{c}\text { O que essas duas } \\
\text { interpretações têm em } \\
\text { comum é que refletem que } \\
\text { a pessoa amada e a relação } \\
\text { recíproca não são objetos } \\
\text { independentes de luto. Na } \\
\text { verdade, essas duas } \\
\text { maneiras de interpretar X } \\
\text { são análogas. Eles } \\
\text { simplesmente mudam a } \\
\text { perspectiva da pessoa para } \\
\text { o relacionamento, porque } \\
\text { se originam de pontos de } \\
\text { vista em que o objetivo é } \\
\text { encontrar o elemento } \\
\text { central do amor. }\end{array}$ & 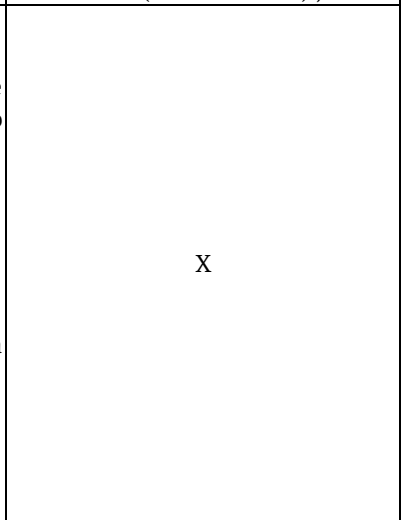 \\
\hline $\begin{array}{c}\text { Suicidal Risk Following } \\
\text { the Termination of } \\
\text { Romantic Relationships. }\end{array}$ & $\begin{array}{c}\text { O objetivo principal deste estudo foi } \\
\text { determinar se os marcadores de risco } \\
\text { específicos para o suicídio estão } \\
\text { relacionados ao nível de compromisso } \\
\text { de um indivíduo com o } \\
\text { relacionamento amoroso antes de sua } \\
\text { dissolução. }\end{array}$ & \begin{tabular}{|c} 
O objetivo deste estudo foi \\
examinar se o \\
compromisso e o \\
investimento estão ligados \\
ao risco de suicídio em \\
uma amostra de adultos (n \\
$=$ 208) nos Estados Unidos \\
com idades entre 18 e 64 \\
anos que vivenciaram o \\
rompimento de um \\
relacionamento romântico \\
significativo dentro do \\
últimos 3 meses.
\end{tabular} & \begin{tabular}{|c|} 
Este estudo indica que o \\
alto comprometimento \\
com um relacionamento \\
amoroso pode servir como \\
fator de risco para \\
depressão e, portanto, \\
para suicídio quando o \\
relacionamento é \\
encerrado.
\end{tabular} & $\begin{array}{c}\text { Amostra de adultos }(\mathrm{n}=208) \text { nos } \\
\text { Estados Unidos com idades entre } 18 \\
\text { e } 64 \text { anos que vivenciaram o } \\
\text { rompimento de um relacionamento } \\
\text { romântico. }\end{array}$ \\
\hline
\end{tabular}




\begin{tabular}{|c|c|c|c|c|}
\hline $\begin{array}{l}\text { Transitions in romantic } \\
\text { relationships and } \\
\text { development of self- } \\
\text { esteem. }\end{array}$ & $\begin{array}{l}\text { Testamos se transições importantes } \\
\text { no domínio dos relacionamentos } \\
\text { românticos (ou seja, iniciar um } \\
\text { relacionamento, casar e terminar) } \\
\text { explicam por que os indivíduos } \\
\text { diferem na trajetória de auto-estima } \\
\text { particular que seguem. }\end{array}$ & \begin{tabular}{|c|} 
Os dados vieram de um \\
estudo longitudinal \\
alemão com uma grande \\
amostra de 3 coortes \\
nacionalmente \\
representativas de \\
adolescentes tardios e \\
adultos jovens (total $\mathrm{N}=$ \\
9.069). As análises foram \\
baseadas em 4 avaliações \\
em um período de 3 anos.
\end{tabular} & \begin{tabular}{|} 
Os resultados têm \\
implicações significativas \\
porque mostram que a \\
autoestima influencia as \\
transições importantes \\
ocorrem no domínio do \\
relacionamento e que, por \\
sua vez, vivenciar essas \\
transições influencia o \\
desenvolvimento posterior \\
da autoestima.
\end{tabular} & $\begin{array}{l}\text { Amostra de } 3 \text { coortes } \\
\text { nacionalmente representativas de } \\
\text { adolescentes tardios e adultos } \\
\text { jovens (total } \mathrm{N}=9.069 \text { ). }\end{array}$ \\
\hline $\begin{array}{l}\text { Sentimentos } \\
\text { predominantes após o } \\
\text { término de um } \\
\text { relacionamento } \\
\text { amoroso }\end{array}$ & $\begin{array}{l}\text { O objetivo deste trabalho foi } \\
\text { investigar os sentimentos que } \\
\text { predominam após o término de } \\
\text { relacionamentos amorosos e as } \\
\text { diferenças de intensidade quanto ao } \\
\text { gênero, iniciativa de término e } \\
\text { duração do relacionamento. }\end{array}$ & \begin{tabular}{|c|} 
Foi construída uma escala \\
de atitudes baseada no \\
modelo Likert, contendo \\
37 afirmativas referentes a \\
sentimentos negativos e \\
positivos, e estabeleceu-se \\
uma equivalência entre as \\
expressões da escala e a \\
atribuição de valor. \\
\end{tabular} & \begin{tabular}{|} 
De um modo geral, a \\
separação provoca abalo \\
emotivo tanto em homens \\
como em mulheres, nas \\
diferentes situações.
\end{tabular} & $\begin{array}{c}\text { Participaram da pesquisa } 68 \\
\text { sujeitos, com idades entre } 17 \text { e } 44 \\
\text { anos, sendo } 37 \text { homens e } 31 \\
\text { mulheres. }\end{array}$ \\
\hline $\begin{array}{l}\text { Facing a breakup: } \\
\text { Electromyographic } \\
\text { responses moderate } \\
\text { self-concept recovery } \\
\text { following a romantic } \\
\text { separation }\end{array}$ & $\begin{array}{c}\text { Rompimentos românticos levantam } \\
\text { questões fundamentais sobre o eu: } \\
\text { Quem sou eu sem meu parceiro?. Este } \\
\text { estudo examinou a reorganização do } \\
\text { autoconceito e o bem-estar } \\
\text { psicológico ao longo de um período de } \\
8 \text { semanas nos meses seguintes ao } \\
\text { rompimento. }\end{array}$ & Análises multiníveis. & \begin{tabular}{|c|} 
A interação entre o \\
autorrelato e os dados \\
psicofisiológicos forneceu \\
informações sobre a \\
importância da \\
recuperação do \\
autoconceito para o ajuste \\
pós-separação, não \\
explorada por nenhum dos \\
métodos isoladamente.
\end{tabular} & $\begin{array}{c}\text { Os participantes foram } 70 \text { ( } 22 \\
\text { homens) estudantes universitários } \\
\text { em uma grande universidade no } \\
\text { sudoeste dos Estados Unidos (idade } \\
\text { média = } 18,91 \text { anos, SD = .99 anos) } \\
\text { que tiveram uma separação } \\
\text { romântica em média } 4,2 \text { meses } \\
\text { antes de entrar no estudo ( } \mathrm{SD}= \\
3,83 \text { meses). }\end{array}$ \\
\hline $\begin{array}{c}\text { The psychology of } \\
\text { breakup sex: Exploring } \\
\text { the motivational factors } \\
\text { and affective } \\
\text { consequences of post- } \\
\text { breakup sexual activity }\end{array}$ & $\begin{array}{c}\text { A cultura popular divulgou } \\
\text { recentemente um comportamento } \\
\text { aparentemente novo pós-separação, } \\
\text { chamado sexo na separação. Embora a } \\
\text { mídia expresse os benefícios da } \\
\text { participação em sexo de separação, } \\
\text { não há pesquisas que apóiem esses } \\
\text { benefícios alegados. A pesquisa atual } \\
\text { foi projetada para começar a entender } \\
\text { melhor esse comportamento pós- } \\
\text { separação. }\end{array}$ & \begin{tabular}{|c|} 
No primeiro estudo, \\
examinamos como \\
experiências sexuais \\
anteriores de término \\
fizeram os indivíduos se \\
sentirem e como as \\
pessoas prevêem que se \\
sentiriam no futuro $(\mathrm{n}=$ \\
212). O segundo estudo ( \\
$\mathrm{n}=585)$ investigou por que \\
homens e mulheres \\
praticam sexo de \\
separação. \\
\end{tabular} & \begin{tabular}{|} 
Os dois estudos revelaram \\
que o sexo na separação \\
pode ter motivações \\
diferentes (e pode ter \\
consequências \\
psicológicas diferentes) \\
para homens e mulheres e \\
pode não ser tão benéfico \\
quanto a mídia sugere.
\end{tabular} & $\begin{array}{l}\text { Primeiro estudo: } 212 \text { participantes. } \\
\text { Segundo estudo: } 585 \text { participantes. }\end{array}$ \\
\hline $\begin{array}{l}\text { The Dark Triad and } \\
\text { break-up distress }\end{array}$ & $\begin{array}{c}\text { Foi, portanto, hipotetizado que altos } \\
\text { níveis de características da Tríade } \\
\text { Negra seriam preditores de menor } \\
\text { sofrimento de rompimento. }\end{array}$ & $\begin{array}{c}\text { Os participantes } \\
\text { completaram a escala The } \\
\text { Short Dark } \\
\text { Triad, uma medida de } \\
\text { autorrelato de } 27 \text { itens. } \\
\text { Essa medida continha três } \\
\text { subescalas de nove itens, } \\
\text { uma para cada um dos três } \\
\text { traços da Tríade Negra: } \\
\text { narcisismo, psicopatia e } \\
\text { maquiavelismo. Os } \\
\text { participantes responderam } \\
\text { aos itens usando uma } \\
\text { escala Likert de } 5 \text { pontos } \\
\text { variando de } 1 \text { (discordo } \\
\text { totalmente) a } 5 \text { (concordo } \\
\text { plenamente). Os } \\
\text { participantes também } \\
\text { completaram a Escala do } \\
\text { modelo de investimento } \\
\text { de auto-relato de } 21 \text { itens. } \\
\text { Além disso, os } \\
\text { participantes completaram } \\
\text { uma medida } \\
\text { de auto-relato de } 16 \text { itens } \\
\text { de angústia na separação }\end{array}$ & \begin{tabular}{|} 
Os resultados mostraram, \\
no entanto, que o \\
maquiavelismo e a \\
psicopatia mostraram \\
correlações positivas de \\
ordem zero com o \\
sofrimento do término, e o \\
narcisismo não mostrou \\
associação com o \\
sofrimento do término. \\
\end{tabular} & $\begin{array}{c}\text { No total, } 264 \text { participantes } \\
\text { permaneceram (96 homens, } 167 .\end{array}$ \\
\hline \begin{tabular}{|} 
Predicting post-breakup \\
distress and growth in \\
emerging adulthood: \\
The roles of relationship \\
satisfaction and \\
emotion regulation
\end{tabular} & $\begin{array}{l}\text { Examinar o papel da satisfação no } \\
\text { relacionamento e as estratégias de } \\
\text { regulação da emoção. }\end{array}$ & \begin{tabular}{|c|} 
Utilizou medidas de \\
autorrelato para examinar \\
o papel da satisfação no \\
relacionamento e as \\
estratégias de regulação da \\
emoção avaliadas aos 20 \\
anos de idade na previsão \\
do sofrimento do \\
rompimento e do
\end{tabular} & $\begin{array}{c}\text { As descobertas destacam } \\
\text { as maneiras pelas quais as } \\
\text { estratégias de regulação } \\
\text { emocional podem ajudar } \\
\text { os adultos emergentes a } \\
\text { lidar com estressores } \\
\text { relacionais, como } \\
\text { separações. }\end{array}$ & $\begin{array}{l}\text { Amostra de adultos emergentes (N } \\
\quad=110 ; 72 \% \text { mulheres). }\end{array}$ \\
\hline
\end{tabular}




\begin{tabular}{|c|c|c|c|c|}
\hline & & $\begin{array}{c}\text { crescimento pós- } \\
\text { traumático três anos } \\
\text { depois. }\end{array}$ & & \\
\hline $\begin{array}{c}\text { A vivência do luto em } \\
\text { decorrência do término } \\
\text { de relacionamentos } \\
\text { amorosos }\end{array}$ & \begin{tabular}{|c|} 
O objetivo geral deste trabalho é \\
averiguar como o luto, em de- \\
corrência do término de \\
relacionamentos amorosos, \\
manifesta-se na subjetividade \\
humana. São objetivos específicos: \\
compreender as múltiplas formas \\
encontradas pelas pessoas de \\
superacão da dor e conhecer os modos \\
de vivenciar, na atualidade, \\
separacões e lutos sofridos pelo fim de \\
relacionamento.
\end{tabular} & $\begin{array}{c}\text { Foi aplicado um } \\
\text { questionário com escalas } \\
\text { de atitude tipo Likert. }\end{array}$ & \begin{tabular}{|c|} 
A vivência do luto \\
apresenta-se \\
progressivamente menos \\
ligada à demonstracãa da \\
dor, devido à prevalência \\
de vínculos mais \\
superficiais e menos \\
compromissados.
\end{tabular} & $\begin{array}{l}\text { Amostra de } 106 \text { pessoas, } 57 \\
\text { mulheres e } 49 \text { homens. }\end{array}$ \\
\hline \begin{tabular}{|c|} 
Benefit Finding and \\
Psychological \\
Adjustment Following a \\
Non-Marital \\
Relationship Breakup
\end{tabular} & $\begin{array}{l}\text { Examinamos o papel adaptativo de } \\
\text { encontrar benefícios em um } \\
\text { rompimento não-matrimonial. }\end{array}$ & $\begin{array}{l}\text { Completaram as medidas } \\
\text { de descoberta de } \\
\text { benefícios, o impacto do } \\
\text { evento e o ajuste. }\end{array}$ & $\begin{array}{c}\text { Este estudo fornece } \\
\text { suporte empírico para } \\
\text { encontrar benefícios em } \\
\text { um rompimento de } \\
\text { relacionamento não } \\
\text { conjugal. } \\
\end{array}$ & 140 participantes. \\
\hline $\begin{array}{c}\text { Romantic relationship } \\
\text { breakup: An } \\
\text { experimental model to } \\
\text { study effects of stress on } \\
\text { depression (-like) } \\
\text { symptoms }\end{array}$ & \begin{tabular}{|c|} 
O objetivo principal de nosso estudo \\
foi investigar: 1) se os indivíduos com \\
um rompimento de relacionamento \\
amoroso recente (" desgosto ") \\
demonstram sintomas de depressão, \\
2) como descrever as características \\
do desgosto com base em dados de \\
uma bateria de questionários \\
abrangente e 3) se esta descrição pode \\
capturar a gravidade dos sintomas de \\
depressão. Secundariamente, \\
estávamos interessados nas diferenças \\
de gênero no que diz respeito aos \\
objetivos do estudo acima. Indivíduos \\
que tiveram um rompimento de \\
relacionamento nos seis meses \\
anteriores $(\mathrm{N}=71$ ) ou estão em um \\
relacionamento amoroso ( $\mathrm{N}=46$ ) \\
participaram de nosso estudo. \\
\end{tabular} & $\begin{array}{c}\text { Uma bateria de } \\
\text { questionários foi } \\
\text { administrada para adquirir } \\
\text { informações relacionadas } \\
\text { à depressão, humor, } \\
\text { separação e (antigo) } \\
\text { relacionamento. Análise } \\
\text { de componentes principais } \\
\text { com bootstrapping de } \\
\text { Procrustes foi realizada } \\
\text { para extrair componentes } \\
\text { dos dados do questionário. }\end{array}$ & \begin{tabular}{|c|} 
Dessa forma, o \\
enfrentamento \\
relacionado ao estresse e a \\
vulnerabilidade à \\
depressão podem ser \\
estudados em novas \\
pesquisas. propomos que a \\
experiência de um \\
rompimento de \\
relacionamento amoroso é \\
um modelo experimental \\
viável para examinar os \\
sintomas de depressão em \\
indivíduos sem transtorno \\
psiquiátrico.
\end{tabular} & $\begin{array}{l}\text { (117) Assuntos que tiveram uma } \\
\text { separação de relacionamento nos } \\
\text { seis meses anteriores }(\mathrm{N}=71) \text { ou } \\
\text { estão em um relacionamento } \\
\text { romântico }(\mathrm{N}=46) \text { participaram de } \\
\text { nosso estudo. }\end{array}$ \\
\hline $\begin{array}{c}\text { Working Memory } \\
\text { Alterations After a } \\
\text { Romantic Relationship } \\
\text { Breakup }\end{array}$ & $\begin{array}{c}\text { Investigamos se a experiência de um } \\
\text { rompimento de relacionamento está } \\
\text { associada a alterações da memória de } \\
\text { trabalho e se isso está relacionado à } \\
\text { gravidade dos sintomas depressivos. }\end{array}$ & Estudo fMRI. & \begin{tabular}{|c|} 
Nossos resultados sugerem \\
que o efeito de uma \\
separação é acompanhado \\
por alterações de memória \\
de trabalho dependentes \\
da carga de trabalho. \\
Portanto, propomos que \\
essa população pode ser \\
potencialmente usada para \\
investigar a interação \\
entre estresse, \\
funcionamento cognitivo e \\
depressão.to de \\
relacionamento está \\
associada a alterações da \\
memória de trabalho e se \\
isso está relacionado à \\
gravidade dos sintomas \\
depressivos. \\
\end{tabular} & $\begin{array}{l}\text { Homens e mulheres que tiveram um } \\
\text { rompimento de relacionamento } \\
\text { romântico nos últimos } 6 \text { meses } \\
\text { (duração do relacionamento antes } \\
\text { do rompimento de pelo menos } 6 \\
\text { meses) - grupo de desgosto (71 } \\
\text { sujeitos). Homens e mulheres em } \\
\text { um relacionamento amoroso foram } \\
\text { inclúdos no grupo de } \\
\text { relacionamento (46 sujeitos). }\end{array}$ \\
\hline
\end{tabular}

"O símbolo "X" faz jus a falta de informação sobre o tópico específico. Fonte: os autores (2021).

No Quadro 1 e novamente exemplificado na Tabela 2, foi possível verificar um quantificado maior de artigos indexados e coletados no Google Acadêmico com 59,40\% em comparação ao BVS/Lilacs com 21,88\%. Além disso, concentrando os menores quantitativos de artigos, encontram-se o SciELO com 9,35\%, PubMED com 6,25\% e o Pepsic com 3,12\%. 
Tabela 2. Demonstrativo da quantidade de artigos por indexador.

\begin{tabular}{ccccc}
\hline GOOGLE ACADÊMICO & BVS LILACS & PUBMED & SCIELO & PEPSIC \\
\hline 19 & 7 & 2 & 3 & 1 \\
\hline & Fonte: os autores (2021).
\end{tabular}

Ao observar a quantidade de produções no período de 2006 a 2021 através do Quadro 1 e da Tabela 3, constatou-se uma maior concentração de artigos selecionados e publicados em 2016 e 2018, seguido de uma disposição com uma menor disparidade no ano de 2019. Por fim, os anos de 2006, 2010, 2012 e 2021 concentram o menor quantitativo de artigos entre os anos investigados. Em resumo, os anos de 2016 e 2018, aparentemente, foram o período de maior produção científica acerca da temática proposta.

Tabela 3. Demonstrativo da quantidade de artigos selecionados em cada ano.

\begin{tabular}{lc}
\hline Ano & Quantidade de artigos \\
\hline 2006 & 1 \\
2010 & 1 \\
2011 & 1 \\
2012 & 2 \\
2013 & 3 \\
2014 & 2 \\
2015 & 3 \\
2016 & 4 \\
2017 & 3 \\
2018 & 3 \\
2019 & 5 \\
2020 & 3 \\
& 3 \\
&
\end{tabular}

\section{Efeitos psicológicos negativos pós-término}

O período pós-término de relacionamento é considerado, por vez, um processo difícil de ser enfrentado por aquele que passa. Isso se dá, sobretudo, aos efeitos psicológicos negativos que comumente ocorrem por inúmeros motivos. Embora existam outros efeitos a se considerar, há alguns que são mais comuns, como: tristeza, raiva, angústia, baixa autoestima, luto, ansiedade e, até mesmo depressão. Além disso, é valido ressaltar que alguns desses efeitos, de certa forma, fazem parte da vida de qualquer sujeito. No entanto, níveis elevados e certa predominância desses sentimentos podem ser considerados indicativos de sofrimento psíquico significativos. Portanto, no geral, os términos dos relacionamentos amorosos, por vez, exacerbam esses níveis e produzem essa constância nesses sentimentos.

Em um estudo realizado por Bieski e Zordan (2014) acerca da vivência de adultos jovens ao término do relacionamento amoroso em um comparativo entre homens e mulheres, identificou-se que mulheres apresentam com maior intensidade os sentimentos de desprezo pelo ex-parceiro, medo da solidão, tristeza e mágoa, raiva e choro. Já os homens apresentam maiores sentimentos de culpa e arrependimento que mulheres, embora também demonstrem tristeza e mágoa, bem como irritação.

No entanto, DeLecce e Weisfeld (2016), ao investigarem as diferenças sexuais nas emoções após o término do relacionamento em dados de autorrelato de 392 participantes, encontraram como resultado que homens e mulheres, no que se refere aos sentimentos negativos, apesar de ambos apresentarem raiva, tristeza e solidão, não divergiam na intensidade dos sentimentos.

Em um estudo com 286 universitários que nunca se casaram e que relataram ter experimentado uma perda romântica por meio de um ou mais rompimentos, os universitários relataram sentir tristeza, depressão, insônia, perda de apetite, retraimento social, ciúme, perda de autoestima, sensação de fracasso e desesperança (Carter, Knox \& Hall, 2018). Atendo-se ainda a esses efeitos, em outra produção realizada a partir de uma amostra de 101 estudantes universitários que encerraram seu relacionamento amoroso não conjugal nos últimos dois anos na Turquia, encontram-se sentimentos de infelicidade, raiva e, em especial, sensação de desamparo (Barutcu \& Aydin, 2013)

Bastos, Rocha e De Almeida (2019), através de um método quantitativo, buscaram compreender melhor a sintomatologia do luto prolongado, TEPT e amargura em fim de relacionamento. Os autores destacam o quanto o término de relacionamento pode causar quadros clínicos que podem comprometer a saúde do sujeito, sobretudo o luto vivenciado após uma separação amorosa, processo este que causa bastante sofrimento psíquico e que em muitos casos pode vir a causar maior sofrimento que o luto de morte. Para além do luto, os autores também sugerem que o amarguramento é presente nos términos de relacionamento, 
compreendido, então, enquanto uma emoção de maior potencial para a desregulação emocional, portanto, favorecendo o desenvolvimento de quadros psicopatológicos.

Cabe ainda mencionar que Bastos, Rocha e De Almeida (2019), a partir de sua amostra com 100 participantes entre 18 e 36 anos e a aplicação de questionários sociodemográficos e utilização de escalas, também encontraram como resultado que indivíduos do gênero feminino possuem índices mais elevados de sintomatologia traumática do que o gênero masculino. No caso do amarguramento, sua alta prevalência ocorre quando há uma separação inesperada.

Ainda sobre o luto, ao investigar a sua manifestação na subjetividade humana através dos términos de relacionamentos amorosos, Rosa, Valente e Oliveira (2013) encontraram uma certa regularidade do luto após os términos. A partir desse encontro, os autores demarcam os principais sintomas encontrados, tais como tristeza e indiferença. Os resultados partiram de uma amostra de 106 pessoas distribuídas segundo sexo e idade, sendo 57 mulheres e 49 homens, em que tanto mulheres e homens, independentemente da idade, apresentaram indiferença e tristeza como o principal sentimento em decorrência do término.

Ao examinar as ligações entre separações específicas e angústia, sintomas depressivos e memórias de relacionamento de diferentes valências, Del Palacio-González, Clark e O'Sullivan (2017a) mencionam que indivíduos que não desejaram o rompimento do relacionamento experimentaram sintomas depressivos e de angústia no rompimento. Além disso, as memórias consideradas positivas e negativas mais frequentes acerca do relacionamento foram ambas relacionadas a sintomas depressivos e de angústia mais elevados. Conforme os autores puderam concluir, os maiores índices de memórias consideradas positivas estiveram associados a níveis mais altos de sintomas de angústia após o término de um relacionamento não conjugal, mas não estavam relacionados a sintomas depressivos. Já em relação às memórias negativas, sua maior frequência esteve associada a sintomas depressivos elevados e de angústia.

Outros achados acrescentam e corroboram com a prerrogativa dos sintomas negativos após o término de um relacionamento amoroso. Em uma amostra de 100 participantes, constatou-se a presença de pensamentos intrusivos, experiências emocionais intensas, sentimentos de solidão e vazio, distúrbios do sono e anedonia (Bronfman et al., 2016). Segundo os autores, os resultados sugerem uma maior incidência de sentimentos de angústia nos indivíduos do sexo feminino, acabando por destacar a possibilidade do desenvolvimento de sintomas e comportamentos considerados depressivos. Igualmente, outro estudo com 220 participantes (66,8\% mulheres), realizado por Garabito et al. (2020), apontam a incidência da depressão em indivíduos que passam e/ou passaram por um término de relacionamento, evidenciando um acometimento maior em mulheres. No caso em questão, os resultados encontrados mencionam mal-estar geral, depressão, desesperança e ideação suicida.

Dooley, Fitzgerald e Giollabhui (2015), com uma grande amostra de adolescentes (3.094 mulheres e 2.936 homens) matriculados em 732 escolas, encontraram que adolescentes que tiveram uma experiência de um rompimento de relacionamento romântico apresentavam níveis mais elevados de depressão, diferentemente dos adolescentes que nunca estiveram em um relacionamento amoroso.

De acordo com Harvey e Karpinski (2016), angústia, sofrimento psicológico e humor deprimido são de fato extremamente presentes no término de relacionamentos amorosos. Contudo, ao investigarem os 217 participantes que compuseram sua amostra, concluíram que, quando existe apoio social, o sofrimento psicológico é menor frente à restrição social. Em vista disso, o apoio social saudável ajuda a superar o fim de um relacionamento e seus efeitos negativos.

Segundo Samios, Henson e Simpson (2014), o fim do relacionamento é um preditor significativo de ansiedade e depressão. A partir da aplicação de escalas para medir ansiedade, depressão e estresse em 140 pessoas de uma comunidade universitária em Queensland, Austrália, que tiveram uma separação de relacionamento não conjugal nos 12 meses anteriores, os autores relataram que há sentimentos negativos preponderantes após o término de relacionamentos. No entanto, outras variáveis devem ser consideradas para medir o nível de sofrimento de cada um. Tomando como exemplo, ainda segundo os autores, as pessoas cujo parceiro iniciou a separação apresentaram maiores índices de depressão em contraste com o fato de que aqueles que estavam namorando novamente após a separação tiveram índices menores. Além disso, aqueles que atribuíram a separação a algo sobre si mesmos relataram maior depressão. Ademais, atribuir a separação à outra pessoa (outra atribuição) estava relacionado a menos ansiedade e atribuir a separação a algo no ambiente (atribuição ambiental) estava relacionado à maior ansiedade.

Conforme o estudo produzido por Verhallen et al. (2019), ao investigar 117 participantes que tiveram uma separação de relacionamento nos seis meses anteriores $(n=71)$ ou permaneciam em um relacionamento romântico $(n=46)$, participantes que tiveram uma separação de relacionamento apresentavam escores mais altos nos níveis de depressão do que os participantes ainda em um relacionamento. Além disso, de acordo 
com os autores, além dos níveis de depressão, sentimento de rejeição, traição, raiva, tristeza e solidão, pensamentos intrusivos e desapontamento também são demasiadamente presentes após uma separação.

Enfim, Francoeur et al. (2020) demonstrou que muito dos prejuízos psicológicos apresentados após um término de relacionamento, sobretudo o desenvolvimento de transtornos psiquiátricos, podem ter uma correlação com eventos passados, nesse caso, com os níveis de maus-tratos na infância. Investigando uma amostra com 483 alunos da Faculdade de Artes e Ciências de uma grande universidade canadense que haviam passado por uma separação nos últimos três meses, os autores concluíram que aqueles que passaram por maiores níveis de maus-tratos na infância eram menos resilientes e, portanto, apresentavam mais sofrimento, angústia e transtornos psiquiátricos, diferentemente daqueles que tiveram menos maus-tratos.

\section{Efeitos psicológicos positivos pós-término}

Ao pensar em términos de relacionamentos amorosos, é comum os associarmos aos efeitos negativos que estiveram ou irão estar presentes no evento. Contudo, embora em menor proporção, a literatura aponta algumas evidências acerca dos pontos positivos que podem ser encontrados.

De acordo com Rosa, Valente e Oliveira (2013), embora em menor proporção (ao menos no caso de sua amostra de participantes), términos de relacionamentos amorosos podem trazer como efeito positivo a sensação de alívio. Da mesma maneira, Marcondes, Trierweiler e Cruz (2006), em um estudo realizado com 68 participantes com idades entre 17 e 44 anos (37 homens e 31 mulheres), constataram que os sentimentos após o término dos relacionamentos amorosos podem ser positivos. Em seus resultados, os autores demonstraram que os términos podem vir a manifestar sensação de liberdade, pensamentos positivos, aumento da autoestima, satisfação com a nova vida e motivações para novas possibilidades da vida.

Semelhantemente, Verhallen et al. (2019) encontrou dentre seus achados negativos alguns efeitos positivos que corroboram com os dados há pouco apresentados, tais como: sensação de alívio e independência, assim como sentimentos de esperança.

Além desses sentimentos, a felicidade também é destacada (Barutcu \& Aydin, 2013). Segundo Bielski e Zordan (2014), o sentimento de felicidade pode aparecer enquanto uma realização após o término de relacionamento. Na amostra selecionada pelos autores, é destacado que homens e mulheres podem apresentar sentimentos de felicidade após a separação; no entanto, em seus escores, os autores concluíram que homens são os que mais apresentam sentimentos positivos após o término de um relacionamento amoroso.

Diferentemente, DeLecce e Weisfeld (2016), investigando as diferenças emocionais entre os sexos em casos de rompimento do relacionamento, encontraram que mulheres apresentaram níveis significativamente mais elevados do que homens no que se refere à felicidade. Esses dados foram apresentados a partir dos resultados de sua amostra (392 participantes).

Por fim, além dos efeitos positivos e negativos, algumas estratégias aparecem como solução para esses efeitos pós-términos de relacionamento, nesse caso, os negativos. Para aliviar as dores e potencializar o processo de superação, o melhor remédio seria o tempo (Garabito et al., 2020) e um processo de avaliação cognitiva e racional dos fatos (Norona et al., 2018), uma vez que, realizando esse procedimento avaliativo, não reprimimos os pensamentos negativos; portanto, resultando em uma melhora significativa. Por outro lado, quando suprimimos tais pensamentos negativos, fica nítido um maior sofrimento psíquico e uma maior desregulação emocional, acrescenta o autor.

\section{Implicações comportamentais após o rompimento de um relacionamento amoroso}

Para além dos efeitos psicológicos, algumas implicações comportamentais também se mostram decorrentes do rompimento de um relacionamento amoroso.

Dentre esses comportamentos, o comportamento perseguidor, ou stalking, se encontra como o principal e pode ser compreendido como um conjunto de comportamentos que envolvem "assédio e ameaças, em que um indivíduo se envolve repetidamente em atos como seguir alguém, aparecer em sua casa ou local de trabalho, assediá-lo por telefone, escrever e enviar cartas [...]” (Borges \& Dell’Aglio, 2019, p. 415). Assim, torna-se possível também pressupor que tal comportamento se apresenta, por vez, como resultado dos efeitos psicológicos negativos do rompimento do relacionamento.

Objetivando elucidar acerca da incidência de stalking após o término de um namoro ou relacionamento amoroso durante a adolescência, assim como seus efeitos psicológicos, Borges e Dell'Aglio (2019) observaram, através de uma amostra de 527 adolescentes entre 14 e 19 anos, alunos de dez escolas de ensino médio públicas e privadas da região metropolitana de Porto Alegre, diversos aspectos relacionados tanto às vítimas 
como às não vítimas do comportamento perseguidor. A partir de seus resultados, os autores concluíram que mulheres são mais perseguidas do que os homens, sendo vítimas de assédio e invasão. Nos casos, também verificou-se que o comportamento durou seis meses ou mais após o término.

Além disso, ainda de acordo com os autores, quando são observadas as diferenças nos sintomas de estresse, depressão e na pontuação EDAE-A (Escala de Depressão, Ansiedade e Estresse para Adolescentes), as mulheres também são mais afetadas quando relacionado à perseguição. $O$ relacionamento em que já existe violência psicológica e física tem grandes chances de ocorrer o comportamento perseguidor. Assim sendo, impactos negativos na saúde mental como ansiedade, estresse e depressão podem estar relacionados com o comportamento de perseguição na pós-separação.

De Smet, Loeys e Buysse (2012), investigando 396 adultos divorciados, encontram que os comportamentos mais prevalentes dentre esses indivíduos eram o de observar o ex-companheiro, monitorar o ex-companheiro e fazer expressões exageradas de afeto. Embora os resultados indicassem uma menor proporção, comportamentos ameaçadores e agressivos também eram presentes, como aparecer em locais de forma ameaçadora, coagir sexualmente o ex-parceiro, deixar ou enviar objetos ameaçadores, sequestrar ou restringir fisicamente o ex-parceiro.

Igualmente, em outro estudo, De Smet et al. (2015) ao investigar a presença do comportamento indesejado de perseguição (UPB) em 631 ex-parceiros adultos, encontrou, tal como no estudo citado no parágrafo anterior, a presença de comportamentos como monitoramento do parceiro, deixar mensagens indesejadas de afeto e até mesmo aqueles considerados extremos, como aparecer aos locais de maneira ameaçadora, deixar objetos ameaçadores, bem como sequestrar ou restringir fisicamente o ex-parceiro.

De maneira mais específica, homens estão mais propensos a enviar mensagens e presentes indesejados do que mulheres, assim como também foi possível observar diferenças entre gêneros opostos e do mesmo sexo em relação à percepção que o ex-parceiro tem, sendo identificado que parceiros de mesmo sexo sentem-se menos ameaçados (De Smet et al., 2015). Ainda de acordo com os autores, um outro aspecto é a frequência do UPB em parceiros clínicos, que é bastante superior aos que não possuem indicação clínica, sendo mais um indicador que prediz o comportamento em estudo. Ademais, o comportamento de perseguição indesejado tem uma maior probabilidade de ocorrer no parceiro que não escolheu pelo término do relacionamento.

Segundo DeLecce e Weisfeld (2016), após o rompimento, indivíduos podem apresentar comportamentos de contato como ligar, enviar mensagens de texto, outras comunicações online, desculpar-se e pedir uma segunda chance. O interessante a se destacar em seus resultados é que para os comportamentos de ligar ou deixar recados, os indivíduos demonstram maiores probabilidades de apresentá-los quando seus ex-parceiros iniciaram a separação. Isso se dá, sobretudo, em comparação com aqueles que indicaram que não iniciaram a separação ou que a decisão foi mútua.

Além dos comportamentos apresentados, o comportamento criminoso e agressivo também aparece enquanto uma possibilidade. Larson, Sweeten e Piquero (2016), examinando os efeitos do rompimento do relacionamento sobre o crime entre os jovens envolvidos com a justiça, partiram de um estudo longitudinal de 1354 (14\% mulheres) jovens julgados dos sistemas de tribunais juvenis e adultos em Phoenix e Filadélfia para a produção de resultados acerca dessa associação entre comportamentos criminosos e fim de relacionamento.

De acordo com os autores, há um aumento de ofensas no período do pós-rompimento do relacionamento, assim como o término de relacionamento entre coabitantes indica maior incidência de crime que o término de um namoro. No entanto, em relação a um namoro estável, a coabitação estável está associada a menos agressões. Por fim, os autores também sugerem que os laços sociais, características psicossociais e a influência dos pares induzem significativamente o aumento de ofensas.

\section{Considerações finais}

Em vista da magnitude dos desdobramentos possíveis de um término de relacionamento sobre a vida de qualquer ser humano, seja do ponto de vista psicológico ou comportamental, a partir da produção deste estudo, buscou-se sistematizar as principais possíveis implicações psicológicas e comportamentais resultantes do rompimento de um relacionamento amoroso.

Primeiramente, foi possível concluir que, ao falar do rompimento de um relacionamento amoroso, as implicações podem ser compreendidas enquanto psicológicas (fatores positivos e negativos) e comportamentais.

Entre as principais implicações psicológicas negativas, concluímos que o rompimento de um relacionamento pode gerar: ansiedade, depressão, angústia, raiva, tristeza, luto, baixa autoestima e a sensação de desamparo. Quanto aos achados sobre as positivas, destacam-se: alívio, memórias positivas e sentimento de liberdade. Já a respeito das implicações comportamentais, concluímos que os términos podem ocasionar em: comportamentos de perseguição, provocação e até mesmo criminoso. 
Além disso, tomando essas conclusões, também foi possível identificar que os graus dessas implicações podem, por vez, ser medidos de acordo com quem escolheu terminar em contraste com quem não optou terminar o relacionamento. Outrossim, no que se refere ao gênero, os estudos, em sua maioria, apresentavam amostras com indivíduos do sexo feminino e masculino. Logo, pode-se afirmar que as implicações são presentes em ambos os sexos, não obstante o comportamento criminoso e perseguidor apresente maior relação com o sexo masculino.

Assim, através do mapeamento dos achados acerca das implicações psicológicas e comportamentais do término de um relacionamento amoroso, tornou-se possível organizar em único local os principais achados que corroboram para a elucidação e ampliação do debate referente a tal temática, resultando, portanto, em uma maior acessibilidade a essas informações, sobretudo no âmbito da literatura brasileira.

A limitação desse estudo encontra-se, em especial, no fato de que embora os estudos apresentassem amostras de ambos os gêneros, a delimitação de algumas implicações psicológicas e comportamentais não ficaram totalmente claras em que intensidade elas se apresentavam ao serem compreendidas na diferença entre os sexos. Além disso, os estudos encontrados, em sua maioria, davam maior ênfase às implicações consideradas negativas (ou de fato encontravam em sua maioria os efeitos negativos), o que acaba por sugerir três possíveis hipóteses: 1) há um maior interesse pelos efeitos considerados negativos, portanto justifica-se esses achados; 2) os efeitos negativos de fato são mais preponderantes que os positivos e 3) houve uma limitação no processo de busca desse estudo. Contudo, independente dessas hipóteses, no geral, os estudos pouco apresentaram os efeitos positivos; melhor dizendo, não houve estudos que tiveram como objetivo principal apresentar estritamente esses efeitos. Sendo assim, tornam-se necessárias maiores investigações em busca de melhores evidências científicas.

Por fim, sugerimos e enfatizamos a importância de pesquisar e ampliar a discussão acerca das implicações psicológicas de um rompimento de relacionamento amoroso, sobretudo atendo-se de maneira estrita aos fatores positivos. Já ao restante (fatores negativos e comportamentais de modo geral), cabe a realização de outras pesquisas atendo-se ao desenvolvimento ou agravamento de outras psicopatologias. Enfim, a realização de estudos com amostras brasileiras que visem averiguar e confirmar os achados aqui mapeados e organizados, assim como ampliar a partir das sugestões elencadas, torna-se um caminho viável para pesquisas futuras.

\section{Referências}

Alexander, A. L. (2008). Relationship resources for coping with unfulfilled standards in dating relationships: Commitment, satisfaction, and closeness. Journal of Social and Personal Relationships, 25, 725-747.

Barutcu, K. F., \& Aydin, Y. C. (2013). The scale for emotional reactions following the breakup. Procedia-Social and Behavioral Sciences, 84, 786-790.

Bastos, V., Rocha, J. C., \& Almeida, T. de. (2019). Os efeitos do rompimento de um relacionamento amoroso em estudantes universitários. Psicologia, Saúde \& Doenças, 20(2), 402-413.

Bielski, D., \& Zordan, E. (2014). Sentimentos predominantes, após o término do relacionamento amoroso, no início da adultez jovem. Perspectiva Erechim, 38(144), 17-24.

Borges, J. L., \& Dell'Aglio, D. D. (2019). Stalking following the breakup of dating relationships in adolescence. Trends in Psychology, 27(2), 413-426.

Brenner, R. E., \& Vogel, D. L. (2015). Measuring thought content valence after a breakup: Development of the Positive and Negative Ex-Relationship Thoughts (PANERT) scale. Journal of Counseling Psychology, 62(3), 476-487.

Bronfman, G., Ladd-Luthringshauser, H., Goodman, L. R., \& Sockol, L. E. (2016). Predictors of breakup distress among residential college students. College Student Affairs Journal, 34(3), 3-12.

Carter, K. R., Knox, D., \& Hall, S. S. (2018). Romantic breakup: Difficult loss for some but not for others. Journal of Loss and Trauma, 23(8), 698-714.

De Smet, O., Loeys, T., \& Buysse, A. (2012). Post-breakup unwanted pursuit: A refined analysis of the role of romantic relationship characteristics. Journal of Family Violence, 27(5), 437-452.

De Smet, O., Uzieblo, K., Loeys, T., Buysse, A., \& Onraedt, T. (2015). Unwanted pursuit behavior after breakup: Occurrence, risk factors, and gender differences. Journal of family violence, 30(6), 753-767.

Del Palacio-González, A., Clark, D. A., \& O’Sullivan, L. F. (2017a). Distress severity following a romantic breakup is associated with positive relationship memories among emerging adults. Emerging Adulthood, 5(4), 259-267. 
Del Palacio-González, A., Clark, D. A., \& O'Sullivan, L. F. (2017b). Cognitive processing in the aftermath of relationship dissolution: Associations with concurrent and prospective distress and posttraumatic growth. Stress and Health, 33(5), 540-548.

DeLecce, T., \& Weisfeld, G. (2016). An evolutionary explanation for sex differences in nonmarital breakup experiences. Adaptive Human Behavior and Physiology, 2(3), 234-251.

Dooley, B., Fitzgerald, A., \& Giollabhui, N. M. (2015). The risk and protective factors associated with depression and anxiety in a national sample of Irish adolescents. Irish journal of psychological medicine, 32(1), 93-105.

Fisher, H. E., Brown, L. L., Aron, A., Strong, G., \& Mashek, D. (2010). Reward, addiction, and emotion regulation systems associated with rejection in love. Journal of neurophysiology, 104(1), 51-60.

Francoeur, A., Lecomte, T., Daigneault, I., Brassard, A., Lecours, V., \& Hache-Labelle, C. (2020). Social Cognition as Mediator of Romantic Breakup Adjustment in Young Adults Who Experienced Childhood Maltreatment. Journal of Aggression, Maltreatment \& Trauma, 29(9), 1125-1142.

Garabito, S., García, F. E., Neira, M., \& Puentes, E. (2020). Ruptura de pareja en adultos jóvenes y salud mental: estrategias de afrontamiento ante el estrés del término de una relación. Psychologia. Avances de la Disciplina, 14(1), 47-59. Epub January 26, 2021.

García, F. E., \& Ilabaca M., D. (2013). Ruptura de pareja, afrontamiento y bienestar psicológico en adultos jóvenes. Ajayu Órgano de Difusión Científica del Departamento de Psicología UCBSP, 11(2), 42-60.

Gillbert, S. P., \& Sifers, S. K. (2011). Bouncing back from a breakup: Attachment, Time perspective. Mental health, and Romantic Loss. Journal of College Student Psychotherapy, 25, 295-310.

Harvey, A. B., \& Karpinski, A. (2016). The impact of social constraints on adjustment following a romantic breakup. Personal Relationships, 23(3), 396-408.

Larson, M., Sweeten, G., \& Piquero, A. R. (2016). With or Without You? Contextualizing the Impact of Romantic Relationship Breakup on Crime Among Serious Adolescent Offenders. Journal of youth and adolescence, 45(1), 54-72.

Lopez-Cantero, P. (2018). The Break-Up Check: Exploring Romantic Love through Relationship Terminations. Philosophia 46, 689-703.

Love, H. A., Nalbone, D. P., Hecker, L. L., Sweeney, K. A., \& Dharnidharka, P. (2018). Suicidal Risk Following the Termination of Romantic Relationships. Crisis, 39(3), 166-174.

Luciano, E. C., \& Orth, U. (2017). Transitions in romantic relationships and development of self-esteem. Journal of personality and social psychology, 112(2), 307-328.

Marcondes, M. V., Trierweiler, M., \& Cruz, Roberto Moraes. (2006). Sentimentos predominantes após o término de um relacionamento amoroso: Predominant feelings after the end of a love relationship. Psicologia: ciência e profissão, 26(1), 94-105.

Mason, A. E., Law, R. W., Bryan, A. E., Portley, R. M., \& Sbarra, D. A. (2012). Facing a breakup: Electromyographic responses moderate self-concept recovery following a romantic separation. Personal Relationships, 19(3), 551-568.

Moran, J. B., Wade, T. J., \& Murray, D. R. (2020). The psychology of breakup sex: Exploring the motivational factors and affective consequences of post-breakup sexual activity. Evolutionary Psychology, 18(3), 1-14.

Moroz, S., Chen, S., Daljeet, K. N., \& Campbell, L. (2018). The Dark Triad and break-up distress. Personality and Individual Differences, 132, 52-59.

Norona, J. C., Scharf, M., Welsh, D. P., \& Shulman, S. (2018). Predicting post-breakup distress and growth in emerging adulthood: The roles of relationship satisfaction and emotion regulation. Journal of adolescence, 63, 191-193.

Robak, R. W., \& Weitzman, S. P. (1998). The nature of grief: Loss of love relationships in young adulthood. Journal of Personal and Interpersonal Loss, 3, 205-216.

Rosa, H. R., de Castro Valente, M. L. L., \& de Oliveira, M. M. (2013). A vivência do luto em decorrencia do término de relacionamentos amorosos. Revista Estudos, 17(17), 173-194.

Rother, Edna Terezinha. (2007). Revisão sistemática X revisão narrativa. Acta Paulista de Enfermagem [online]. 20 (2), v-vi.

Samios, C., Henson, D. F., \& Simpson, H. J. (2014). Benefit finding and psychological adjustment following a non-marital relationship breakup. Journal of Relationships Research, 5. 
Verhallen, A. M., Renken, R. J., Marsman, J. C., \& Ter Horst, G. J. (2019). Romantic relationship breakup: An experimental model to study effects of stress on depression (-like) symptoms. PloS one, 14(5), e0217320.

Verhallen, A. M., Renken, R. J., Marsman, J. C., \& Ter Horst, G. J. (2021). Working Memory Alterations After a Romantic Relationship Breakup. Frontiers in behavioral neuroscience, 15, 657264.

Vosgerau, D. S. R \& Romanowski, J. P. (2014). Estudos de revisão: implicações conceituais e metodológicas. Revista Diálogo Educacional, 14 (41), 165-189.

\section{Minicurrículo}

Rodrigo Barbosa Nascimento. Acadêmico do curso de Psicologia da Escola de Ciências da Saúde e Bem-estar da Universidade Salvador - Laureate International Universities (UNIFACS), Feira de Santana - BA. Graduando em Filosofia pela Universidade Católica de Brasília. Membro do Núcleo de Estudos em Comportamento, Filosofia e Psicanálise (NECOFIP).

Emanuel Santos de Araujo Filho. Acadêmico do curso de Psicologia da Escola de Ciências da Saúde e Bemestar da Universidade Salvador - Laureate International Universities (UNIFACS), Feira de Santana - BA. Membro do Núcleo de Estudos em Comportamento, Filosofia e Psicanálise (NECOFIP).

Gabriela de Lima Cerqueira. Acadêmica do curso de Psicologia da Escola de Ciências da Saúde e Bem-estar da Universidade Salvador - Laureate International Universities (UNIFACS), Feira de Santana - BA. Membro do Núcleo de Estudos em Comportamento, Filosofia e Psicanálise (NECOFIP).

Daniela Gomes Carneiro. Acadêmica do curso Psicologia da Escola de Ciências da Saúde e Bem-estar da Universidade Salvador - Laureate International Universities (UNIFACS), Feira de Santana - BA. Membro do Núcleo de Estudos em Comportamento, Filosofia e Psicanálise (NECOFIP).

Emilly Santos da Silva Carmo. Academica do curso de psicologia da Escola de Ciências da Saúde e Bem-estar da Universidade Salvador - Laureate International Universities (UNIFACS), Feira de Santana - BA. Membro do Núcleo de Estudos em Comportamento, Filosofia e Psicanálise (NECOFIP).

Como citar: Nascimento, R.B., Araujo Filho, E.S., Cerqueira, G.L., Carneiro, D.G., \& Carmo, E.S.S. 2021. Após o fim de um relacionamento amoroso: uma revisão narrativa. Pubsaúde, 7, a233. DOI: https://dx.doi.org/10.31533/pubsaude7.a233

Recebido: 8 jun. 2021.

Revisado e aceito: 24 jun. 2021.

Conflito de interesse: os autores declaram, em relação aos produtos e companhias descritos nesse artigo, não ter interesses associativos, comerciais, de propriedade ou financeiros que representem conflito de interesse.

Licenciamento: Este artigo é publicado na modalidade Acesso Aberto sob a licença Creative Commons Atribuição 4.0 (CC-BY 4.0). 